
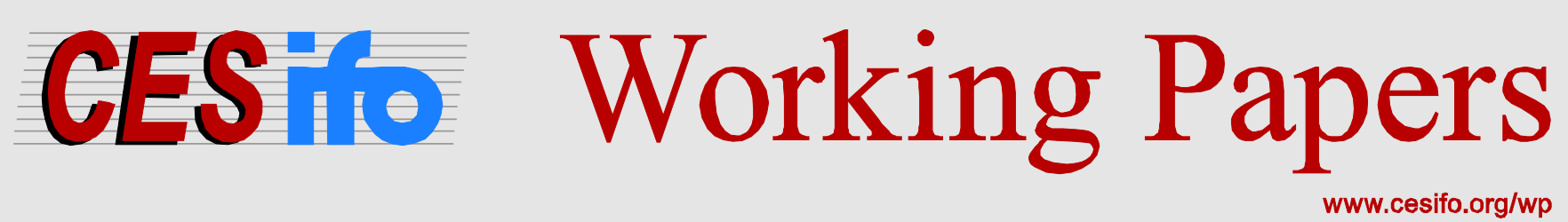

\title{
Petty Corruption and Citizen Reports
}

\author{
Charles Angelucci \\ Antonio Russo
}

\author{
CESIFO WORKING PAPER NO. 5528 \\ CATEGORY 9: RESOURCE AND ENVIRONMENT ECONOMICS \\ ORIGINAL VERSION: SEPTEMBER 2015 \\ THIS VERSION: MARCH 2017
}

An electronic version of the paper may be downloaded

- from the SSRN website:

- from the RePEc website:

- from the CESifo website:

wWw.SSRN.com

www.RePEc.org

www.CESifo-group.org/wp 


\title{
Petty Corruption and Citizen Reports
}

\begin{abstract}
To enforce regulations, governments often delegate power to public officials. However, officials may have incentives to abuse their discretionary power and engage in bribery or extortion. Efforts to monitor and curb such abuses have inspired interest in using new communication technologies to gather information directly from citizens. In our model, entrepreneurs must comply with regulations before undertaking an activity. Officials verify their compliance and may engage in corruption. In line with existing work, the government tolerates corruption and weak enforcement when it does not communicate with entrepreneurs. However, we show that a simple incentive scheme in which entrepreneurs can report noncompliance both deters corruption and improves regulatory enforcement. In an extension, we incorporate intermediaries and show their presence makes the scheme more valuable.
\end{abstract}

JEL-Code: H110, H830, O170, D730.

Keywords: corruption, extortion, self-reporting, bureaucracy intermediaries.

\author{
Charles Angelucci \\ Columbia Business School \\ New York / NY / USA \\ ca2630@gsb.columbia.edu
}

\author{
Antonio Russo \\ ETH Zurich \\ Zurich / Switzerland \\ russo@kof.ethz.ch
}

November 4, 2016

A previous version of this paper circulated under the title "Petty Corruption and Citizen Feedback.” We thank Vesa Kanniainen, Thomas Groll, Patrick Kennedy, Simone Meraglia, Nicola Persico, Giancarlo Spagnolo, Yossi Spiegel, Eric Verhoogen, and Xiao Yu Wang for useful comments. We also thank audiences at ETH Zurich, Tinbergen Institute, the Workshop on Political Economy at IEB Barcelona, the CESifo Public Sector Economics conference, and the Applied Economics Workshop in Petralia Sottana. Part of this research was conducted while Angelucci visited INSEAD. The author is grateful to this institution for its hospitality. Opinions and errors are ours. The Supplementary Appendix is available on the authors' websites. 


\section{Introduction}

Petty corruption is widespread in the developing world and affects the lowest levels of government, dealing with ordinary citizens and firms (e.g., tax collectors and labor inspectors). ${ }^{1}$ One of its consequences is to undermine the enforcement of regulations designed to protect society from risks and hazards (e.g., pollution, accidents, etc.). A difficulty in the struggle against corruption is to provide low-ranking officials with the incentives to adequately perform their duty. Two issues, particularly salient in developing countries, give rise to this challenge. First, public officials often have considerable discretionary power: little transparency surrounds the decisions they make. Second, officials are rarely held accountable for misbehaving (e.g., because the judicial system is weak, or because supervisors are also corrupt). ${ }^{2}$ As previous literature has emphasized, given such difficulties, even benevolent governments may have no choice but to tolerate corruption and weak regulatory enforcement (see, e.g., Finan et al. (2015) and Khalil et al. (2010)).

To improve monitoring and oversight of public officials, it is increasingly common for governments to gather information from citizens at the receiving end of public services. In particular, a number of countries have recently implemented feedback schemes whereby users of public services can file complaints about government officials. ${ }^{3,4}$ In this paper, we argue in favor of a different but complementary approach to gathering information. Specifically, we make the case that communicating with citizens about their own behavior can also help efforts to reduce corruption. We show that allowing individuals or companies to report their failure to comply with rules (i.e., allowing them to "self-report") and tying government officials' pay to these reports can help prevent corruption in public administrations and ensure that regulations are properly enforced. A virtue of our selfreporting scheme is its simplicity: it does not require the intervention of monitors or courts, nor does the government need to verify the accuracy of the reports.

We develop a model in which a population of entrepreneurs is required to comply with some

\footnotetext{
${ }^{1}$ See Olken and Pande (2012) and Banerjee et al. (2012) for recent surveys.

${ }^{2}$ Also, some governments may benefit from corruption and have no incentives to deter it.

${ }^{3}$ For instance, see Ghana's Whistleblower Act and Punjab's Citizen Feedback Model (Callen and Hasanain (2011)). Another example is the anti-corruption website recently created in Kenya (www.president.go.ke/en/category/corruption.php), where people can report cases of malfeasance. An obvious reason behind the growing interest in these schemes is that improvements in ICT have dramatically reduced the cost of filing, registering, and processing feedback. See, e.g., The Economist (September 24th, 2009).

${ }^{4}$ See Amegashie (2016) on whether complaints can discipline officials. Mookherjee and Png (1992) consider complaints in a model without bribery. Prendergast (2003) looks at complaints as a means of bureaucratic oversight.
} 
regulation (e.g., environmental law) upon undertaking an activity (e.g., the production of a good). ${ }^{5}$ Compliance with regulation is privately costly, but avoids generating negative externalities (e.g., pollution). Government officials are matched with entrepreneurs to perform a screening function. They verify whether entrepreneurs comply, and either grant or deny the permit necessary to carry out the activity. ${ }^{6}$ The government observes whether an official grants a permit, but not the information upon which the decision is based. As a result, officials can engage in (i) bribery, by obtaining money from noncompliant entrepreneurs in exchange for the permit, and (ii) extortion, by forcing compliant entrepreneurs to pay a bribe to be issued the permit. Whereas bribery weakens the effectiveness of regulation, extortion deters entrepreneurs from applying for the permit. Finally, officials face possible sanctions when misbehaving (or, equivalently, incur some cost of falsifying information), but these sanctions alone are insufficient to deter corruption.

We first analyze the case in which the government does not communicate with the entrepreneurs. To deter bribery, the government must reward officials who deny permits by paying them an amount of money equal to the bribe the entrepreneurs would be willing to pay (minus the expected sanction). However, such a policy invites extortion: it makes systematically refusing permits in the officials' interest. As a result, the government cannot do better than to offer low-powered incentives, and tolerate bribery in order to deter extortion (Hindriks et al. (1999), Khalil et al. (2010)). The enforcement of regulation is then weak, because noncompliant entrepreneurs are able to receive a permit in exchange for a bribe.

We then allow the government to communicate with the entrepreneurs and show that doing so not only deters both bribery and extortion, but also that the optimal mechanism takes the form of a simple self-reporting scheme. Specifically, under the scheme, entrepreneurs are allowed to report their noncompliance to the government before their officials' decision regarding whether to grant the permit. The government denies the permit to the entrepreneurs who self-report (possibly in exchange for a small compensation). Finally, officials receive a bonus when the entrepreneur they are paired with self-reports, and otherwise receive a flat payment independent of their decision regarding the permit. As a result of these features, absent a bribe, officials whose entrepreneurs do not self-report are

\footnotetext{
${ }^{5}$ We refer to citizens as entrepreneurs, but our analysis is more general. It applies, for instance, to the issuance of drivers' licenses, for which abundant evidence of corruption exists (e.g., Bertrand et al., 2007). We provide further examples in Section 5.

${ }^{6}$ In the model, delegating the decision to issue permits to officials is weakly optimal.
} 
better off granting (resp. denying) permits to compliant (resp. noncompliant) entrepreneurs to avoid sanctions (or to avoid the cost of manipulating information). Also, the entrepreneurs who anticipate being denied the permit by their officials may as well self-report. Such a scheme prevents extortion because it is enough for a compliant entrepreneur to refuse to pay a bribe and to not self-report to make it in the official's interest to grant the permit. Moreover, officials have no desire to engage in bribery, (i) because the bonus the government promises them if their entrepreneur self-reports is larger than the bribe the entrepreneur is willing to pay and (ii) because they anticipate that noncompliant entrepreneurs indeed prefer to self-report when unable to bribe their way to the permit. ${ }^{7}$

By deterring corruption, the scheme we propose makes regulation more effective in curbing negative externalities. Nevertheless, adopting this mechanism is not always socially optimal. Because it entails the payment of bonuses to officials, the budget needed to maintain the administration is expanded. As a result, we find that, for communication with the entrepreneurs to be valuable, the cost of allocating the necessary resources must be relatively small compared to the negative externalities society can avoid by taming corruption.

The "citizen feedback" programs recently developed in several countries, such as Punjab's Feedback Model, inspire the mechanism we propose. However, in such programs, feedback is collected with the primary goals of guiding investigations against dishonest officials and administering sanctions. We explore a different, and possibly complementary, use of citizen-provided information. A novelty of our proposal is to empower citizens to directly influence the pay of the officials with whom they interact. By exploiting citizen reports, the government is able to offer officials a high-powered incentive scheme that does not invite extortion. This feature of our scheme is particularly relevant, given that the lack of transparency surrounding officials' decisions often hampers the implementation of effective anti-corruption incentives (OECD (2013, p. 110), Finan et (2015)). ${ }^{8}$ An additional practical concern

\footnotetext{
${ }^{7}$ The logic behind this scheme is not unprecedented and resembles plea bargaining schemes in spirit. For instance, several municipalities in the UK outsource enforcement of parking meters to private companies. To limit abuses, incentive contracts for enforcers stipulate bonuses tied to uncontested tickets. Furthermore, offenders who agree to settle early (thereby admitting their fault) are often entitled to discounts on fines (http://www.economist.com/node/16847086/print, retrieved June 2015).

${ }^{8}$ Several scholars have argued in favor of linking officials' rewards to their performance (see, e.g., Polinsky and Shavell (2000)). The existing evidence on the effectiveness of performance incentives suggests they can be effective if carefully designed (Olken and Pande (2012)). Kahn et al. (2001) study an incentive program for tax collectors in Brazil and find evidence that the program restrained bribery. Khan, Khwaja, and Olken (2014) conduct a field experiment that tests financial incentives for property tax inspectors. They find evidence that incentives make tax collection more effective by reducing the pervasiveness of bribery. See also Furnivall (1956, p.270) for evidence on the role of citizen reports in disciplining officials.
} 
is that incentive systems may be ineffective if they provide broad discretion to higher-level supervisors (e.g., by requiring them to assess citizen reports). However, one strength of our scheme is precisely that ascertaining the accuracy of citizen reports is not necessary, so that the administrators in charge of implementing it are left with little discretion to exercise. Finally, because of the limited informational content required for citizen self-reporting, these reports can be transmitted via very simple and inexpensive communication technologies (e.g., making or receiving a phone call, or sending an SMS).

In the second part of the paper, we introduce bureaucracy intermediaries (e.g, paralegals, brokers, facilitators, etc.). Intermediaries specialize in assisting individuals who must deal with administrations to obtain a government service (e.g., a permit), and are common in developing countries (Bertrand et al. (2007), Fredriksson (2014)). We focus on their ability to facilitate bribery: by developing stable relationships with officials, intermediaries guarantee preferential treatment for their customers, thereby weakening the incentives entrepreneurs have to comply with regulation. Our results suggest the pervasiveness of intermediaries is a by-product of the low-powered incentives provided to officials. We also show that, if properly exploited, the self-reporting scheme may allow the government to deter officials from dealing with intermediaries, thereby strengthening the enforcement of regulation.

Related Literature. A vast literature explores the causes and consequences of corruption in public administrations (see, e.g., Aidt (2009), Banerjee et al. (2012), and Olken and Pande (2012) for surveys). One particularly relevant strand of this literature studies how the design of officials' incentives affects their performance. ${ }^{9}$ Many studies have highlighted a central tension between the goals of enforcing regulations and preventing corruption. (e.g., Hindriks et al. (1999), Polinsky and Shavell (2000), Khalil et al. (2010)). On the one hand, the government must grant public officials sufficient power to properly enforce regulations; on the other hand, officials may have incentives to abuse their discretionary power and engage in bribery or extortion. This tension can be so strong that tolerating some forms of corruption in order to deter others may be optimal. Our contribution is to show how the government can deter both bribery and extortion and properly enforce regulations if it communicates appropriately with citizens.

\footnotetext{
${ }^{9}$ This issue has also been investigated in settings such as law enforcement (e.g., Polinsky and Shavell (2000), Mishra and Mookherjee (2013), Burlando and Motta (2016)) and tax collection (e.g., Hindriks, et al. (1999)).
} 
Our model is also related to a strand of the literature that investigates the scope for schemes in which individuals can report having paid or accepted a bribe. For instance, Bucirossi and Spagnolo $(2001,2006)$ study the consequences of leniency policies on corruption, and Dufwenberg and Spagnolo (2015) examine Basu's (2011) proposal to "legalize bribe giving."10 Contrary to these models, our focus is on reporting by citizens of their own choice of whether to comply with public rules, and on how to formally incorporate such reports into public officials' incentive pay. In addition, in our model, corruption is explicitly embedded in a regulatory framework. More generally, self-reporting schemes have been extensively studied in the law enforcement and cartel literatures (see, e.g., Innes (1990), Kaplow and Shavell (1994), Motta and Polo (2003), Spagnolo (2005), and Harrington (2008)). ${ }^{11}$

The literature on collusion within organizations has extensively investigated the consequences of bribery and extortion on supervisors' incentives. For instance, Celik (2009) finds a supervisor is useful only if the principal provides the agent with the possibility of blowing the whistle. Felli and Hortala-Vallve (2014) show the principal can design a whistleblowing program to deter bribery, which, unless designed carefully, may invite extortion. Further, Khalil et al. (2010) show that letting bribery occur to deter extortion is optimal, and Vafai (2012) shows that deterring both forms of corruption is possible if information is verifiable.

Our paper also relates to the growing literature on intermediaries. Bertrand et al. (2007) document their relevance for driving examinations in India. Drugov et al. (2014) examine how intermediaries affect the moral costs of corruption. Theoretical studies include Hasker and Okten (2008), Bose and Gangopadhyay (2009), Fredriksson (2014), and Dusha (2015). Our work departs from these by considering citizen-provided reports to the government.

The remainder of the paper is organized as follows. Section 2 presents the model. Section 3 solves the game by first assuming the government does not rely on entrepreneur reports, and then allowing for it. Section 4 presents an extension with bureaucracy intermediaries. Section 5 concludes. Proofs of all propositions and lemmas are relegated to the Appendix. Proofs of additional results and extensions can be found in the Supplementary Appendix.

\footnotetext{
${ }^{10}$ See also Oak (2015) and Wu and Abbink (2013) for, respectively, theoretical and experimental evidence on the reporting of corruption. See Abbink, et al. (2014) on the choice of liability rules to deter extortion. Finally, see Perrotta Berlin and Spagnolo (2015) on self-reporting schemes and corruption in China.

${ }^{11}$ For more recent work, see references in Angelucci and Han (2016).
} 


\section{The Setup}

Consider a government and a continuum of pairs of entrepreneurs and officials of size 1. All players are risk neutral. Entrepreneurs wish to engage in an activity that generates a private benefit $G$. The activity is socially risky in that it imposes damages $D>G$ onto third parties (e.g., pollution) unless entrepreneurs comply with some regulation. If the government allows the activity, it requests that all entrepreneurs comply with regulation and hires officials to verify compliance. Upon verification, entrepreneurs are either granted or denied the permit necessary to undertake the activity. ${ }^{12}$

Actions and Information. Each entrepreneur decides whether to apply for the permit. Applying is costless, but entrepreneurs apply only if their expected payoff is strictly positive. Moreover, entrepreneurs unobservably choose whether to comply $(e=h)$ or not comply $(e=l)$ with regulation. ${ }^{13}$ An entrepreneur imposes damages $D$ on third parties if she has chosen not to comply and yet is granted the permit. In case of damages, the government is unable to infer which entrepreneur is liable. Choosing $e=h$ implies a cost $\psi$ to entrepreneurs, where $\psi$ is i.i.d. across entrepreneurs according to the cumulative distribution function $H(\cdot)$ with support $[0, \bar{\psi}]$. The cost $\psi$ is private information to the entrepreneurs and must be sustained regardless of whether the permit is granted.

Each applicant entrepreneur (she) is randomly paired with an official (he). Within each pair, the official and entrepreneur observe a signal $\sigma$ correlated with the latter's effort choice $e \in\{l, h\}$. Specifically, $\sigma$ can take two values: either $\sigma=c$ ("compliance") or $\sigma=n$ ("non-compliance"). We assume $\operatorname{Pr}(\sigma=c \mid e=h)=1$ and $\operatorname{Pr}(\sigma=n \mid e=l)=\rho$, where $\rho \in(0,1)$. Officials fail to detect all noncompliant entrepreneurs, but compliant entrepreneurs are never detected as noncompliant. ${ }^{14}$ The signal $\sigma$ is observable only to the given official-entrepreneur pair, and having a third party verify it is exceedingly costly. ${ }^{15}$

\footnotetext{
${ }^{12}$ In practice, entrepreneurs may be able to do business without permits (e.g., by operating in the informal sector). Our results are robust to this modification, as long as the gain obtained without a permit is (weakly) smaller than $G$, and as long as the expected harm imposed on society is not excessively larger than $D$.

${ }^{13}$ We model the decision to comply with regulation to capture the distinct consequences of bribery and extortion on welfare. The notation $e \in\{l, h\}$ is meant to capture an effort decision on the part of the entrepreneurs, which can either be high or low.

${ }^{14}$ Allowing for false positives will imply that, even if bribery is deterred, entrepreneurs who choose not to comply with regulation may apply for the permit in the hope of being undetected. We allow this behavior to avoid unrealistic predictions regarding the government's equilibrium wage bill (which would be equal to zero is the technology were perfectly accurate). Conversely, allowing for false negatives would not add interesting insights, nor affect our main results. We rule out this possibility for notational convenience.

${ }^{15}$ The assumption that $\sigma$ is observable to the entrepreneur best fits situations in which little margin exists for
} 
For each entrepreneur-official pair, after having observed $\sigma$, and leaving aside the issue of corruption for the moment, the entrepreneur first communicates with the government by sending a publicly observable message $m_{E} \in M_{E}$. Subsequently, either her associated official or the government-depending on the allocation of authority-publicly rules whether to grant $(r=g)$ or deny $(r=d)$ the permit. When the government retains authority over permits, officials are also requested to send a message $m_{O} \in M_{O}$ prior to the ruling $r$. In these instances, we suppose officials send their message $m_{O}$ after having observed their entrepreneurs' message $m_{E} \cdot{ }^{16}$ For simplicity, we restrict message spaces to contain only two messages: $M_{E} \equiv\left\{m_{E 1}, m_{E 2}\right\}$ and $M_{O} \equiv\left\{m_{O 1}, m_{O 2}\right\} .{ }^{17} \mathrm{In}$ what follows, let $m \equiv\left(m_{O}, m_{E}\right)$. Sending messages is costless, and information is soft: entrepreneurs and officials can send any message independently of $\sigma$. Similarly, when delegated authority over permits, officials enjoy full discretionary power and can choose $r \in\{g, d\}$ independently of $\sigma$.

Mechanisms. For every pair, the government does not observe the associated signal $\sigma$, but it observes (i) the entrepreneur's message $m_{E} \in\left\{m_{E 1}, m_{E 2}\right\}$ and (ii), depending on the allocation of authority, either the official's message $m_{O} \in\left\{m_{O_{1}}, m_{O_{2}}\right\}$ or the official's ruling $r \in\{g, d\}$. Because all officials are identical and randomly matched with entrepreneurs, the government designs and commits to a mechanism that provides identical incentives to all pairs. Also, we suppose wages must be nonnegative, and restrict our attention to deterministic mechanisms. Finally, we do not assume that either retaining or delegating authority over permits (i.e., over the choice $r \in\{g, d\}$ ) is optimal, and instead let the government decide.

Formally, the government specifies a delegation-rule $x\left(m_{E}\right): M_{E} \rightarrow\{0,1\}$ which allocates authority over the choice $r \in\{g, d\}$, where $x\left(m_{E}\right)=1$ means that the government chooses $r \in\{g, d\}$ (the government "retains authority") and $x\left(m_{E}\right)=0$ means that the official chooses $r \in\{g, d\}$ (the interpretation regarding compliance. An example is the regulation of truck weight (Olken and Barron (2009)). A threshold exists, known to both officials and drivers, above which a truck is considered overweight. If the driver knows the amount of cargo on the truck, he is also aware the official observes noncompliance when the truck is weighed. The assumption also avoids complications by ensuring bargaining between officials and entrepreneurs takes place under symmetric information.

${ }^{16}$ We let the message $m_{O}$ be sent after the publicly-observable message $m_{E}$ because we wish entrepreneurs to influence the government's decision whether to delegate authority over the choice $r \in\{g, d\}$ to the officials. Also, this timing limits the scope for multiple equilibria. In practice, as discussed in Section 3, and as suggested by existing schemes, governments can without difficulty ensure such a sequential timing by exploiting basic communication technologies.

${ }^{17}$ This restriction is without loss of generality, as shown in the proof of Proposition 2 in the Appendix. In a nutshell, this is because, in our environment, the government can only hope to elicit information that is common to the entrepreneurs and officials; that is, $\sigma$, which can only take two values. 
goverment "delegates authority"). Notice that whether a given official has authority over the issuance of the permit may depend on his associated entrepreneur's message $m_{E}$.

The government also specifies, for all the pairs for which it retains authority (i.e., for all the pairs such that $x\left(m_{E}\right)=1$ ), (i) a decision-rule $r\left(m_{O}, m_{E}\right): M_{O} \times M_{E} \rightarrow\{g, d\}$ which determines under which pairs of messages it issues the permit and (ii) the officials' schedule of wages $s\left(m_{O}, m_{E}\right): M_{O} \times M_{E} \rightarrow \mathbb{R}^{+}$, where $s_{m_{O}, m_{E}}$ is the wage paid when official and entrepreneur send, respectively, messages $m_{O}$ and $m_{E}$. Further, for all the pairs in which the official is delegated authority (i.e., for all the pairs such that $x\left(m_{E}\right)=0$ ), the government specifies the officials' schedule of wages $s\left(r, m_{E}\right): M_{E} \times\{g, d\} \rightarrow \mathbb{R}^{+}$, where $s_{r, m_{E}}$ is the wage paid when the entrepreneur sends message $m_{E}$ and the official chooses $r .^{18}$

In the course of the analysis, we will show the government is indifferent between retaining and delegating authority over the choice $r \in\{g, d\}$. The rule we adopt then consists of reporting the notationally simplest mechanism. For the sake of conciseness, in the remainder of this section, we suppose the government delegates authority over permits to the officials (i.e., $x\left(m_{E}\right)=0, \forall m_{E}$ ).

The government also affects officials' payoffs by making action recommendations. For instance, the government may recommend officials to grant permits when observing $\sigma=c$ and to deny them when observing $\sigma=n$. Not surprisingly, the government will always recommend not to collect bribes. Officials who deviate from these recommendations face an exogenous expected sanction $\gamma \geq 0$. Alternatively, one can interpret $\gamma$ as a cost that officials must sustain when manipulating information or when hiding bribes. To capture the fact that officials operate in an environment of low accountability, we assume $\gamma$ to be small; specifically, $0 \leq \gamma<\frac{G}{2}$. As we argue below, when $\gamma>\frac{G}{2}$, the government can deter all forms of corruption without the need to communicate with entrepreneurs.

We end with a brief discussion devoted to the method we employ to characterize the optimal mechanism. In this paper, instead of solving the government's optimization problem, we (i) compute an upper bound on the level of welfare any mechanism within the considered class of mechanisms can achieve and (ii) analyze a specific self-reporting scheme which achieves this upper bound (and is thus optimal) whenever communicating with the entrepreneurs is valuable. Under the scheme,

\footnotetext{
${ }^{18}$ Communicating with the officials when the latter have authority over the permits is of no value to the government when officials' wages are contingent on their decision whether to grant the permit.
} 
entrepreneurs are given the opportunity —after observing $\sigma$ but before the ruling $r$ is made — to report their possible noncompliance with regulation to the government. An entrepreneur who "self-reports" is systematically denied the permit, and whether an entrepreneur who does not self-report obtains the permit depends on her official's ruling $r \in\{g, d\}$.

Payoffs. $U(\psi, e, r, m, b)$ denotes an entrepreneur's ex-post payoff. We assume $U(\cdot)$ is additively separable in the gain $G$ (if $r=g$ ), the cost of compliance $\psi$ (if $e=h$ ), and the bribe $b$ paid to the official (if any). For instance, $U=G-b-\psi$ if an entrepreneur is issued a permit after having paid a bribe despite having chosen $e=h$.

Similarly, $V(\sigma, r, m, b)$ denotes an official's ex-post payoff. We assume $V(\cdot)$ is additively separable in the wage $s$, the sanction/cost $\gamma$ (if any), and the bribe $b$ (if any). For instance, $V=s_{g}-\gamma+b$ if an official collects a bribe $b$ from the entrepreneur he is paired with, and (unduly) grants her a permit. ${ }^{19}$

Finally, the government designs (and commits to) its mechanism to maximize the expected level of social welfare, which is equal to the sum of all entrepreneur and officials' expected payoffs, minus the expected level of damages and the expected wage bill. Moreover, we assume a cost $\lambda \geq 1$ to society of making transfers to officials (the "cost of public funds"). ${ }^{20}$ Finally, the government always has the option of banning the activity, in which case welfare is equal to zero. Throughout, we assume $G \leq \bar{\psi}<D$. In words, requesting that, upon undertaking the activity, entrepreneurs comply with regulation is socially optimal. However, undertaking the activity when requested to comply with regulation may not be socially (and privately) optimal. Importantly, if the government could observe all pairs' signal realizations, setting $r=g$ when $\sigma=c$ and $r=d$ when $\sigma=n$ would maximize expected welfare. ${ }^{21}$ We refer to this policy as the "first-best" policy.

Corruption. Because corruption involves agreements that are illicit, no straightforward approach to modelling it exists. ${ }^{22}$ In this paper, we suppose each official, after having observed $\sigma$, possibly makes a take-it-or-leave-it offer to the entrepreneur that specifies a ruling $r$, a message $m_{E}$, and a

\footnotetext{
${ }^{19}$ For simplicity, we ignore officials' participation constraints.

${ }^{20}$ When $\lambda>1$, officials' wages generate deadweight losses. See Laffont and Tirole (1993) on the cost of public funds.

${ }^{21}$ Systematically denying permits would lead to no entrepreneur applying, and thus no economic activity. Systematically granting permits would lead to no entrepreneur opting for compliance, which is undesirable, because $D>G$. Finally, choosing $r=g$ when $\sigma=n$ and $r=d$ when $\sigma=c$ would also lead to no entrepreneur opting to comply.

${ }^{22}$ Moreover, the possibility for the entrepreneurs to communicate with the government raises the complexity of the agreements that entrepreneurs and officials need to enter.
} 
bribe $b$, to be paid as soon as the deal is struck. We assume the entrepreneur cannot commit to the message $m_{E}$ specified in the deal, and thus require that it be chosen in a sequentially rational way. Furthermore, we assume the official, when designing the deal, cannot commit to a ruling $r$ that occurs out-of-equilibrium (it can, however, commit to the ruling specified in the deal). In other words, should the entrepreneur deviate from the message $m_{E}$ specified in the deal, the official chooses $r$ in a sequentially rational way. ${ }^{23}$ We do not rule out the possibility for officials to make transfers to entrepreneurs. Moreover, we assume officials have full bargaining power when offering deals to entrepreneurs. This assumption is consistent with situations in which citizens have little protection vis-à-vis officials. ${ }^{24}$ An entrepreneur accepts a deal if and only if the payoff it guarantees her is higher than her payoff when she rejects the deal, in which case both players play in a sequentially rational way.

Anticipating the analysis to come, the only deal an entrepreneur and an official may wish to enter involves granting the permit in exchange for a bribe. Formally, after observing $\sigma$, an official solves

$$
\begin{aligned}
\max _{\left\{b, m_{E}\right\}} & V\left(\sigma, g, m_{E}, b\right) \\
\text { s.t. } & U\left(\psi, e, g, m_{E}, b\right) \geq U_{\sigma}^{\prime},
\end{aligned}
$$

and subject to the entrepreneur being better off sending message $m_{E}$. Notationally, $U_{\sigma}^{\prime} \equiv$ $U\left(\psi, e, r_{\sigma}^{\prime}, m_{\sigma}^{\prime}, 0\right)$, where $r_{\sigma}^{\prime}$ and $m_{\sigma}^{\prime}$ denote, respectively, the official's ruling and the message the entrepreneur sends in the absence of a deal, and for a given $\sigma$.

We distinguish between bribery and extortion. Bribery occurs when an official obtains a payment from an entrepreneur found noncompliant (i.e., when $\sigma=n$ ) in return for the permit. Extortion occurs when an official obtains a payment from an entrepreneur found compliant (i.e., when $\sigma=c$ ) in return for the permit. In the baseline version of the model, officials cannot commit to the bribes they will request from the entrepreneurs prior to their interaction with the latter. As a result, officials

\footnotetext{
${ }^{23}$ These assumptions simplify the exposition of the results because they limit the set of agreements officials and entrepreneurs can enter. However, assuming they can enter contracts that specify binding transfers and actions contingent on all possible scenarios leads to identical results (see, for instance, Faure-Grimaud et al. (2003) for such a modeling approach). A previous version of this paper in which this alternative contractual assumption is made is available upon request.

${ }^{24}$ Our main results do not depend on this allocation of bargaining power. A more general treatment, in which we let the bargaining outcome within each official-entrepreneur pair be determined by the Nash Bargaining solution concept, is presented in the Supplementary Appendix.
} 
fail to internalize the impact of corruption on the entrepreneurs' incentives to apply for the permit. Note that, in addition, officials can also abuse their power without engaging in bribery or extortion. Specifically, to pocket as high a wage as possible, officials may be tempted to make a decision $r$ that contrasts with the government's recommendation.

Timing. We summarize the model by presenting the timing of moves: ${ }^{25}$

1. The government decides whether to allow the activity. If the activity is allowed, the government chooses and commits to a schedule of wages $s\left(r, m_{E}\right)$.

2. The entrepreneurs simultaneously decide whether to apply for the permit. If an entrepreneur applies, she chooses her effort level $e \in\{l, h\}$ and is randomly paired with an official. For each pair, a signal $\sigma \in\{c, n\}$ is realized.

3. Each entrepreneur-official pair possibly enters a deal. If a deal is struck, the entrepreneur pays a bribe $b$ to the official. All entrepreneurs send message $m_{E}$ to the government and, subsequently, officials choose $r \in\{g, d\}$.

4. The government observes the entrepreneurs' messages and the officials' decisions, and pays officials' wages according to the schedule $s\left(r, m_{E}\right)$.

We conclude with some final considerations. First, our focus is on pure-strategy equilibria. Second, as in any moral hazard setting, we must address the issue of players' behavior when indifferent between several actions; an issue which in our framework is made slightly more intricate than usual by the fact that entrepreneurs interact with two "principals." We suppose that an official who is indifferent between several actions (or deals to offer his entrepreneur) selects the government's recommended option. As it turns out, as long as $\gamma>0$, this assumption is qualitatively innocuous: a government concerned about the robustness of its mechanism can always break officials' indifference by raising one payment by an arbitrarily small amount. Similarly, we assume that an entrepreneur who is indifferent between accepting her official's deal or rejecting it chooses to accept it. Again, officials can always ensure that entrepreneurs accept their deal by decreasing the bribe they request by an arbitrarily

\footnotetext{
${ }^{25}$ In the exposition of the timing, we anticipate the fact that the only deals officials and entrepreneurs contemplate involve granting the permit in exchange for a bribe. We also anticipate that delegating authority over the permits to the officials is optimal.
} 
small amount. Other than the decision to accept a deal, however, we assume that an entrepreneur who is indifferent between several actions chooses the government's preferred action. ${ }^{26}$

\section{Solving the Model}

We first consider the case of no corruption. Next, we introduce corruption, and characterize the government's optimal policy both when it communicates and when it does not communicate with the entrepreneurs.

\subsection{Incorruptible Government Officials}

Suppose the officials never make deals with the entrepreneurs. Suppose further the government delegates authority over the permits (i.e., over the choice $r \in\{g, d\}$ ) to the officials, and instructs them to grant (deny) permits when they observe $\sigma=c(\sigma=n)$. Officials who grant the permit receive $s_{g}$, and those who deny it receive $s_{d}$. In order to ensure that officials choose $r=g$ when $\sigma=c$ and $r=d$ when $\sigma=n$, the government does not need to communicate with the entrepreneurs and simply sets all wages equal to zero. ${ }^{27}$ As a result, a given entrepreneur intent on applying for the permit complies with regulation if and only if $G-\psi \geq(1-\rho) G$, which simplifies to $\psi \leq \rho G$. The gross benefit of complying is equal to $\rho G$, that is, the increase in the probability that the official observes $\sigma=c$ multiplied by the value of the permit.

Because $\max [G-\psi,(1-\rho) G]>0$ for $\forall \psi$, all entrepreneurs apply for the permit but only a fraction $H(\rho G)$ of them choose to comply. Therefore, if the activity is allowed, the expected level of social welfare-hereafter the "no-corruption" level of welfare-is equal to

$$
W^{N C}=\int_{0}^{\rho G}(G-\psi) d H(\psi)+(1-\rho) \int_{\rho G}^{\bar{\psi}}(G-D) d H(\psi) .
$$

\footnotetext{
${ }^{26}$ Because the class of mechanisms we consider precludes transfers from the government to the entrepreneurs, formally speaking, the government cannot break an entrepreneur's indifference by making an arbitrarily small transfer. We disregard transfers to entrepreneurs for the sake of tractability and because, in many contexts, it would be difficult for governments to offer incentive contracts to citizens/entrepreneurs (for instance, because it would invite abuses). However, in practice, governments may influence citizens/entrepreneurs' payoffs (and break their possible indifference between several actions) with very simple rewards or punishments (e.g., by speeding up the application process). We discuss this issue at greater length and provide specific examples in Section 3. In the Appendix, we show our main insights are unaffected - if anything, they are strengthened - if we allow the government to make a small transfer to the entrepreneurs.

${ }^{27}$ Because the government induces the "first-best" decision rule at zero cost, it follows that retaining authority over the permits cannot improve welfare.
} 
Officials fail to deny the permit to all entrepreneurs who chose $e=l$. It follows that the expected level of damages is positive, and that social welfare is nonnegative if and only if

$$
D \leq D_{0}^{N C} \equiv \frac{G(1-\rho+\rho H(\rho G))-\int_{0}^{\rho G} \psi d H(\psi)}{(1-\rho)(1-H(\rho G))}
$$

When $D>D_{0}^{N C}$, the government cannot do better than ban the activity.

\subsection{Corruptible Government Officials}

\subsubsection{No Communication with the Entrepreneurs}

Suppose now that the officials are corruptible, but that, for exogenous reasons, the government does not communicate with the entrepreneurs. In what follows, we anticipate that it is weakly optimal for the government to delegate authority over the permits to the officials. The proof of this result can be found together with the proof of Proposition 1 in the Appendix. Again, officials who grant the permit receive $s_{g}$ and those who deny it receive $s_{d}$, and again the government instructs them to grant (deny) permits when $\sigma=c(\sigma=n)$. We show that deterring both bribery and extortion is impossible. As a result, either tolerating bribery so as to deter extortion or forbidding the activity is optimal.

Bribery. Consider an official whose signal indicates non-compliance (i.e., $\sigma=n$ ). Ignoring possible bribes, if the official denies the permit, his payoff is equal to $s_{d}$ and the entrepreneur's is equal to 0 . By contrast, if the official unduly grants the permit, his payoff is equal to $s_{g}-\gamma$ and the entrepreneur's is equal to $G$. The pair is thus better off choosing $r=g$ if

$$
s_{g}-\gamma+G>s_{d}
$$

Suppose this inequality holds. If, moreover, $s_{g}-\gamma>s_{d}$, the official chooses $r=g$ without exchanging money: the entrepreneur would reject any request for a bribe, anticipating that granting the permit is in the official's interest. By contrast, if $s_{g}-\gamma \leq s_{d}$, the wage $s_{d}$ is high enough that, absent a bribe, denying the permit is in the official's interest. As a result, and because the official has full bargaining power, he is able to extract a bribe equal to $G$.

Finally, if $s_{d} \geq s_{g}-\gamma+G$, no bribe exists that the entrepreneur is willing to pay and that would 
lead to the official choosing $r=g$. Therefore, for the government to ensure permits are denied when $\sigma=n$, it must necessarily set

$$
s_{d} \geq s_{g}-\gamma+G
$$

Because $G-\gamma>0$, for the government to deter bribery, it must necessarily reward officials who make decisions unfavorable to the entrepreneurs.

Extortion or Framing. Consider now an official whose signal indicates compliance (i.e., $\sigma=c$ ). The pair is better off choosing $r=g$ if $s_{g}+G \geq s_{d}-\gamma$. Suppose this inequality holds. If, moreover, $s_{g} \geq s_{d}-\gamma$, the official chooses $r=g$ without extracting a bribe. Indeed, the wage $s_{g}$ is high enough that granting the permit is in the official's interest: the entrepreneur would reject any request for a bribe. By contrast, if $s_{d}-\gamma>s_{g}$, denying the permit is in the official's interest. As a result, the official extorts a bribe equal to $G$ in return for the permit. Thus, if $s_{g}+G \geq s_{d}-\gamma$, the official always chooses $r=g$ when observing $\sigma=c$, but does so without engaging in extortion only if $s_{g} \geq s_{d}-\gamma$.

Finally, if $s_{d}-\gamma>s_{g}+G$, there does not exist a bribe that the entrepreneur is willing to pay and would lead to the official choosing $r=g$. The official frames the entrepreneur by choosing $r=d$. Summing up, for the government to ensure that officials grant permits without engaging in extortion, it must necessarily set

$$
s_{g} \geq s_{d}-\gamma
$$

Note that, to deter extortion, setting $s_{g}=s_{d}$ is sufficient; that is, making the officials' wages unresponsive to their decisions is sufficient.

Rearranging (3) and (4) leads to the following chain of inequalities: $\gamma \geq s_{d}-s_{g} \geq G-\gamma$, which cannot hold, because $\frac{G}{2}>\gamma$. To prevent bribery, the government must reward officials who deny permits by setting $s_{d}$ sufficiently high. However, doing so means systematically denying permits is in the officials' best interest, thereby paving the way to either extortion or framing. Because of the officials' low accountability, the government is unable to deter all forms of corruption, and must choose between bribery and extortion. ${ }^{28}$

To establish which corrupt behavior should be deterred, let us briefly comment on the distinct consequences on the entrepreneurs' incentives of having either (3) or (4) hold. Suppose (3) holds.

\footnotetext{
${ }^{28}$ In case $\frac{G}{2} \leq \gamma$, the government can deter both bribery and extortion by setting wages appropriately.
} 
Officials deny permits when $\sigma=n$, but either frame or extort entrepreneurs when $\sigma=c$. Because officials who engage in extortion are able to extract the entire value of a permit, the entrepreneurs' gross payoff is equal to zero both in case $\sigma=c$ and $\sigma=n$, and applying for the permit is of no value. As a result, social welfare is equal to zero. ${ }^{29}$

Now suppose (4) holds. Officials grant permits without extracting bribes when $\sigma=c$. By contrast, because (3) does not hold, officials grant permits in exchange for bribes equal to $G$ when $\sigma=n$. An entrepreneur intent on applying thus complies with regulation if and only if

$$
G-\psi \geq(1-\rho) G
$$

which simplifies to $\psi \leq \rho G$. Because $\max [G-\psi,(1-\rho) G]>0$ for $\forall \psi$, all entrepreneurs apply for the permit, but only a fraction $H(\rho G)$ chooses to comply with regulation. Specifically, those who comply do so because their cost of compliance $\psi$ is smaller than the expected bribe $\rho G$ they would pay to obtain the permit if they chose $e=l$. For the remaining entrepreneurs, $\psi$ is large enough that not complying, and running the risk of having to pay the bribe if detected, is rational. Given that bribery is not deterred, all entrepreneurs who choose not to comply obtain the permit.

The next proposition states the government's optimal policy when it does not communicate with the entrepreneurs. In what follows, let $D_{0}^{N S} \equiv \frac{G-\int_{0}^{\rho G} \psi d H(\psi)}{1-H(\rho G)}-\rho \gamma$.

Proposition 1. Suppose the government does not communicate with the entrepreneurs. If $D \leq D_{0}^{N S}$, allowing the activity, delegating authority to the officials, and tolerating bribery so as to prevent extortion is optimal. The officials' optimal wages are $s_{g}=0$ and $s_{d} \in[0, \gamma]$, and the associated level of social welfare is equal to

$$
W^{N S}=\int_{0}^{\rho G}(G-\psi) d H(\psi)+\int_{\rho G}^{\bar{\psi}}(G-D-\rho \gamma) d H(\psi) .
$$

If $D>D_{0}^{N S}$, banning the activity is optimal.

If the government allows the activity, it must tolerate either bribery or extortion. However, the above discussion shows clearly that tolerating extortion can never be a viable option. If bribery is

\footnotetext{
${ }^{29}$ In the Supplementary Appendix, we show that extortion continues to have a more detrimental consequence on welfare than bribery, unless entrepreneurs enjoy particularly high bargaining power.
} 
tolerated, making the officials' wages unresponsive to their decisions (see (4)) is then sufficient, and the government may as well set $s_{d}=s_{g}=0$. It follows that tolerating bribery minimizes the wage bill. Moreover, bribery has a disciplining effect on entrepreneurs. Because those who are detected as noncompliant enjoy a lower payoff than those who are not, many entrepreneurs choose to comply with regulation. The key social cost of allowing bribery is therefore that entrepreneurs who choose not to comply - and obtain the permit via bribery - impose damages $D$ onto third parties.

Comparing the achieved level of welfare in (6) to the "no-corruption" one in (2) is instructive. Although, in both cases, (i) the expected wage bill is zero and (ii) the measure of compliant entrepreneurs is identical (see (5)), welfare when bribery is tolerated is lower than in the "nocorruption" benchmark. As a result, corruption reduces the threshold on the level of damages $D$ above which the government prefers to ban the activity (i.e., $D_{0}^{N S}<D_{0}^{N C}$ ).

\subsubsection{Communication with the Entrepreneurs}

We now allow the government to communicate with the entrepreneurs by asking them to send a message $m_{E} \in\left\{m_{E 1}, m_{E 2}\right\}$ after having observed $\sigma \in\{c, n\}$ but prior to the ruling $r \in\{g, d\}$.

For the sake of brevity, instead of solving the government's optimization problem, we focus on a specific mechanism - a self-reporting scheme - and analyze its properties. First, we show the government is able to deter both bribery and extortion by implementing this scheme, albeit at the cost of a higher wage bill. Second, we compare the level of welfare achieved under the self-reporting scheme to the level of welfare achieved in the absence of communication with the entrepreneurs, and derive conditions under which the scheme raises welfare. In the Appendix, we compute an upper bound on the level of welfare any mechanism within the class of mechanisms we consider can achieve and show that the self-reporting scheme achieves this upper bound whenever communicating with the entrepreneurs is valuable. In other words, the self-reporting scheme is optimal whenever communicating with the entrepreneurs allows the government to achieve a level of welfare higher than that under Proposition 1's policy.

The Self-reporting Scheme. Under the self-reporting scheme, entrepreneurs found noncompliant are instructed to report their noncompliance (or, more precisely, to report having observed $\sigma=n$ ) by sending message $m_{E 1}$. The government denies the permit to all entrepreneurs who "self-report." 
By contrast, whether the entrepreneurs who do not self-report (i.e., those who send message $m_{E 2}$ ) obtain the permit is left to the discretion of their associated officials. In other words, officials are granted authority over permits whenever their associated entrepreneurs do not self-report. Finally, the government pays the wage $s_{a} \equiv s_{m_{O 1}, m_{E 1}}=s_{m_{O 2}, m_{E 1}}$ to the officials whose entrepreneurs self-report, the wage $s_{g} \equiv s_{g, m_{E 2}}$ to the officials who grant permits, and the wage $s_{d} \equiv s_{d, m_{E 2}}$ to the officials who deny permits. As we now show, the government can design the schedule of wages $\left\{s_{g}, s_{d}, s_{a}\right\}$ in a way that makes deterring both extortion and bribery possible.

We revisit the incentives officials have to engage in corruption. Consider extortion first, and recall that, to deter it, the government must set wages in such a way that the threat of framing is not credible. Assume an official and an entrepreneur have not entered into a deal. If the entrepreneur chose not to self-report (i.e., $m_{E}=m_{E 2}$ ), choosing $r=g$ when $\sigma=c$ is in the official's best interest if and only if

$$
s_{g} \geq s_{d}-\gamma
$$

Now consider bribery. If the entrepreneur chose $m_{E}=m_{E 2}$, when $\sigma=n$, an official prefers to deny the permit rather than take a bribe if and only if

$$
s_{d} \geq s_{g}-\gamma+G
$$

where the right-hand side of (8) represents the official's payoff in case of bribery.

As shown in the previous section, satisfying both (7) and (8) is impossible. However, the government can now exploit the wage $s_{a}$ to prevent bribery. To see this, suppose $s_{a}=G-\gamma$ and $s_{g}=s_{d}=0$. In words, the government rewards the officials whose entrepreneurs self-report. Because $s_{g}=s_{d}$, extortion is deterred: it is enough for the compliant entrepreneur not to self-report to make it subsequently rational for her official to grant the permit. By contrast, when $\sigma=n$, entrepreneurs who did not enter a deal with their official are denied the permit regardless of whether they self-report, and may thus just as well self-report. Anticipating this outcome, and because $s_{a}$ is larger than their payoff when engaging in bribery, officials choose not to offer a deal, and thus pocket 
the wage $s_{a} \cdot 30,31$

Notice that, when $\sigma=n$, entrepreneurs do not strictly gain from self-reporting. They are indifferent between self-reporting and not self-reporting, and choose to self-report because it is the government's recommended action. To help intuition, however, one can think of the entrepreneurs who self-report as receiving a small reward from the government. In the appendix, we formally show that our results continue to hold (if anything, they are strengthened) if we modify the model to allow the government to reward the entrepreneurs who self-report. ${ }^{32}$ In practice, a government can compensate an applicant in several ways. For instance, if, as is common, applicants are required to pay an application fee, they can be made eligible for a refund. Alternatively, unsuccessful applicants wishing to apply again could become eligible to have the process expedited, be exempt from future application fees, and so on.

Lemma 1. The government can deter both bribery and extortion by implementing a self-reporting scheme such that

1. the permit is denied to all the entrepreneurs who self-report,

2. whether the entrepreneurs who do not self-report obtain the permit is left to the discretion of their officials, and

3. officials' wages are such that $s_{g}=s_{d}=0<s_{a}=G-\gamma$.

The value of an entrepreneur's report does not lie in its informational content, but in how it affects incentives. On the one hand, entrepreneurs found compliant never self-report. Thus, extortion is deterred, because the officials' pay is then flat. On the other hand, officials know entrepreneurs found noncompliant are better off self-reporting, and thus prefer to pocket the extra wage rather than engage in bribery.

\footnotetext{
${ }^{30}$ One could be concerned about officials and entrepreneurs agreeing on sending $m_{E}=m_{E 1}$ in order to share $s_{a}=G-\gamma$ when $\sigma=c$. However, (i) such a deal is not feasible because sending $m_{E 1}$ would not be sequentially rational for an entrepreneur after having pocketed $b$ and (ii), even if entrepreneurs could somehow commit to $m_{E}=m_{E 1}$, they would refuse the deal because $s_{a}-\gamma=G-2 \gamma<G$ (that is, officials could not compensate the entrepreneurs for forgoing the permit).

${ }^{31}$ In an extension, available in the Supplementary Appendix, we show that if the size of bribes is limited by budgetary constraints for the entrepreneur, so is the level that $s_{a}$ needs to attain in order to deter bribery. Our main results are qualitatively unaffected.

${ }^{32}$ Specifically, in the appendix, we allow the government to make a transfer $t \geq 0$ to the entrepreneurs who self-report. In this modified setup, the self-reporting remains identical except for $s_{a}$ which becomes $s_{a}=G-t-\gamma$.
} 
The scheme we propose resembles institutional arrangements featured in many regulatory systems. Schemes whereby individuals acknowledge noncompliance (often in exchange for a compensation) are common. For instance, in traffic law enforcement, several countries (e.g., France, Italy, and the UK) allow drivers who are issued fines to receive discounts if they acknowledge their wrongdoing. Furthermore, enforcers' wages are often tied to uncontested tickets. Our contribution is to show how these schemes can help in the fight against corruption.

We believe a virtue of our self-reporting scheme is its simplicity, primarily because it does not require the government to assess the validity of the reports. As a result, these reports can consist of very simple (and inexpensive) actions, such as making (or receiving) a phone call or sending text messages from mobile phones. ${ }^{33}$ In addition, because the mechanism disciplines officials simply by conditioning their wage on the entrepreneur's decision to self-report, it minimizes the need to rely on monitors (who may also be corruptible; see, e.g., Duflo et al. (2013) and Mishra (2006)).

Before proceeding further, discussing two features of our scheme is worthwhile. First, we assumed entrepreneurs cannot commit to their message $m_{E}$ while interacting with their official. Noncompliant applicants may otherwise be inclined to commit not to self-report, to make bribery tempting to the officials. Ensuring the entrepreneurs cannot commit not to self-report seems easily achievable. For instance, the scheme can be designed such that the entrepreneurs have the possibility to selfreport only after a certain amount of time has elapsed since the end of their interaction with the official. Second, we have also assumed entrepreneurs can self-report only prior to their officials' decision regarding whether to grant the permit. This assumption implies that officials cannot abuse the scheme by committing to deny the permit. Such a threat, if credible, would make self-reporting rational for compliant entrepreneurs. This outcome can be avoided by ensuring the officials file their final decision only once the interaction with the entrepreneurs has ended, and the latter has decided not to self-report.

Welfare analysis. In the Appendix, we show that the self-reporting scheme is optimal whenever communicating with the entrepreneurs is valuable, that is, whenever the government can raise welfare above the level achieved under the policy outlined in Proposition 1 by communicating with the

\footnotetext{
${ }^{33}$ As the Punjab Feedback Model suggests, governments can keep track of officials' decisions and communicate with citizens with the aid of basic communication technologies (Callen and Hasanain (2011)).
} 
entrepreneurs. The next proposition states the conditions under which communicating with the entrepreneurs (i.e., implementing the self-reporting scheme) is socially optimal. Let $D^{S} \equiv \lambda(G-\gamma)$ and $D_{0}^{S} \equiv \frac{D_{0}^{N S}-\lambda \rho(G-\gamma)}{1-\rho}$, where $S$ and $N S$ stand, respectively, for "scheme" and "no scheme."

Proposition 2. Suppose the cost of public funds is such that $1 \leq \lambda<\frac{D_{0}^{N S}}{G-\gamma}$; then

1. When $D \leq D^{S}$, not communicating with the entrepreneurs, and tolerating bribery so as to prevent extortion by setting $s_{g}=s_{d}=0$, is optimal.

2. When $D^{S}<D \leq D_{0}^{S}$, implementing the self-reporting scheme stated in Lemma 1 is optimal.

3. When $D>D_{0}^{S}$, banning the activity is optimal.

When $\lambda \geq \frac{D_{0}^{N S}}{G-\gamma}$, not communicating with the entrepreneurs, and tolerating bribery so as to prevent extortion by setting $s_{g}=s_{d}=0$, is optimal if and only if $D<D_{0}^{N S}$. Otherwise, banning the activity is optimal.

A review of the advantages and drawbacks of the self-reporting scheme is useful. First, it allows the government to deter not only extortion, but also bribery. As a result, no entrepreneur found ineligible obtains the permit. Also, the government provides incentives to comply with regulation as strong as in the no-corruption benchmark, because an entrepreneur's payoff is equal to $G$ when $\sigma=c$ and to 0 when $\sigma=n .^{34}$ Thus, the expected level of gains and damages the activity generates is identical to that when corruption is infeasible. The drawback is that the government must promise a positive wage $s_{a}$, which increases the government's wage bill. When the self-reporting scheme is implemented, social welfare is equal to

$$
W^{F}=\int_{0}^{\rho G}(G-\psi) d H(\psi)+(1-\rho) \int_{\rho G}^{\bar{\psi}}(G-D) d H(\psi)-(1-H(\rho G)) \rho(\lambda-1)(G-\gamma)
$$

Because of the additional wage bill, the cost $\lambda$ cannot be excessively high for the scheme to be optimal. We find that if $\lambda \leq \frac{D_{0}^{N S}}{G-\gamma}$, the self-reporting scheme dominates the "low-powered" scheme that tolerates bribery stated in Proposition 1, as long as the damages $D$ are large enough but not excessively so (i.e., $\left.D^{S}<D \leq D_{0}^{S}\right) .{ }^{35}$ Paying high wages in order to deter bribery is worthwhile only

\footnotetext{
${ }^{34}$ An entrepreneur chooses $e=h$ if and only if $G-\psi \geq(1-\rho) G$. Because $\max [G-\psi,(1-\rho) G]>0$, all entrepreneurs apply and the share of compliant entrepreneurs is $H(\rho G)$.

${ }^{35}$ To show that $\frac{D_{0}^{N S}}{G-\gamma}>1$, observe that the inequality $G-\gamma<\frac{G-\int_{0}^{\rho G} \psi d H(\psi)}{1-H(\rho G)}-\rho \gamma$ simplifies to $(G-(1-\rho) \gamma)(1-H(\rho G))<G-\int_{0}^{\rho G} \psi d H(\psi)$. This last inequality holds because $\int_{0}^{\rho G} \psi d H(\psi)<G H(\rho G)$ implies $G-\int_{0}^{\rho G} \psi d H(\psi)>G(1-H(\rho G))$.
} 
if the damages the government avoids are large enough. Nevertheless, because the officials' verification technology is imperfect, denying permits to all entrepreneurs who chose $e=l$ is not possible even with the self-reporting scheme. As a result, the government cannot do better than to ban the activity when damages are very high (i.e., $D>D_{0}^{S}$ ). Finally, if $\lambda$ is high (i.e., $\lambda>\frac{D_{0}^{N S}}{G-\gamma}$ ), exploiting entrepreneur reports is never optimal. The government then adopts the same policy as in Proposition 1.

\section{Bureaucracy Intermediaries}

We have so far assumed officials and entrepreneurs interact directly. We now extend the model to consider indirect interaction through intermediaries (e.g., paralegals, brokers, facilitators, etc.). This extension is of interest because intermediaries are ubiquitous in developing countries (Bertrand et al. (2007), Fredriksson (2014)). Anecdotal evidence suggests intermediaries perform several functions. On the one hand, they reduce the transaction costs of dealing with the administration. On the other hand, intermediaries also facilitate corruption: by developing relationships with officials, they guarantee preferential treatment to their customers. Because our interest is in the interplay between corruption and intermediaries, we ignore the cost-saving aspect of the services they provide.

We first show the pervasiveness of intermediaries is related to the low-powered incentives provided to officials. Without the self-reporting scheme, the optimal wage schedule is such that officials collect bribes via intermediaries when entrepreneurs' willingness to pay for the permit is large enough. Next, we show that the self-reporting scheme can reduce the extent of intermediated corruption. ${ }^{36}$ In this extension, we take it for granted that delegating authority over the permits to the officials is weakly optimal. ${ }^{37}$

Modified setup. The action space of the entrepreneurs is expanded to allow them to acquire the permit via an intermediary. Specifically, $e=\{h, l, i\}$, where $i$ denotes "using an intermediary." An intermediary guarantees a permit by means of his connection with the official. Hence, if $e=i$, the official always chooses $r=g$. Obtaining the permit via the intermediary does not require any compliance effort on the entrepreneur's part. However, a fee $\varphi$ has to be paid for the intermediary's

\footnotetext{
${ }^{36}$ For the sake of brevity, in this extension, we do not verify whether the self-reporting scheme is optimal. Instead, we provide conditions under which it raises welfare compared to the benchmark in which the government does not communicate with the entrepreneurs.

${ }^{37} \mathrm{~A}$ proof of this result is available upon request.
} 
service. In turn, the intermediary pays a price $p$ to the official. In other words, the official sells the permit to the intermediary, who then re-sells it to the entrepreneur. For simplicity, intermediaries sustain no costs (except for the money paid to the official) and make no profits (e.g., because of free entry). As a result, $\varphi=p$ in equilibrium; relaxing these assumptions would slightly complicate the analysis without altering the results.

One of the reasons intermediaries enjoy preferential access to officials is that they develop longterm relationships. Such relationships require trust and commitment not to renege on agreements. Accordingly, we assume each official can commit to $p$ before entrepreneurs choose $e .{ }^{38}$ By contrast, officials cannot commit to the bribes they request when interacting with entrepreneurs directly - the relationship between officials and entrepreneurs being "one shot". Hence, if $e=\{h, l\}$ are chosen, the game continues as in our basic setup. We assume that if an entrepreneur has chosen to deal with the official directly, she cannot revise her decision at a later stage. We also assume that when an entrepreneur is indifferent between $e=i$ and $e=l$, she chooses $e=i$. If the self-reporting scheme is in place, as before, $s_{a}$ denotes the wage paid to an official whose entrepreneur self-reports and $s_{g}$ (resp. $s_{d}$ ) denotes the wage paid to an official who grants (resp. denies) the permit. All entrepreneurs who self-report are denied the permit, and whether the entrepreneurs who do not self-report obtain the permit is left to the discretion of their officials.

Whether a permit has been issued by means of an intermediary is unobservable. To facilitate comparison with previous results, we maintain the assumption that entrepreneurs are matched exogenously with officials and, consequently, with (one of) the intermediaries with whom the official regularly deals (we assume the set of intermediaries associated with each official is exogenous). Finally, to streamline exposition, we assume $\psi \sim U[0, \bar{\psi}]$. Also, we suppose $D$ is never so large that the government cannot do better than to ban the activity.

Timing. The timing of the game is as follows:

1. The government chooses the officials' wage schedule $\left\{s_{g}, s_{d}, s_{a}\right\}$.

2. Each official sets $p$, and intermediaries set $\varphi=p$.

\footnotetext{
${ }^{38}$ This modeling approach is similar to that adopted in Shleifer and Vishny in the sense that here the officials choose their price $p$ taking into account its effect on the demand for permits. By contrast, in the baseline model, the officials are unable to commit to a bribe $b$ prior to the entrepreneurs' application choice.
} 
3. Each entrepreneur is paired with an official and an intermediary, and chooses $e=\{h, l, i\}$.

4. All entrepreneurs who chose $e=i$ pay $\varphi=p$ to the intermediary. The latter transfers $p$ to the official, who grants the permit regardless of $\sigma$. For all other entrepreneurs, the game proceeds as in the baseline model.

Entrepreneurs' incentives. Consider an entrepreneur with cost of compliance $\psi$. If she chooses $e=\{h, l\}$, she obtains the same payoffs as in Section 3. If instead $e=i$, her payoff is $G-p$. Let $\tilde{\psi}$ denote the compliance cost of the entrepreneur who is indifferent regarding whether to comply with regulation; that is, let $\tilde{\psi}$ be defined as

$$
U(\tilde{\psi}, h)=\max [U(l), U(i)]
$$

To save on notation, we drop the arguments other than $e$ in $U(\cdot)$. A measure $H(\tilde{\psi})$ of entrepreneurs chooses $e=h$, and the remainder choose either $e=l$ or $e=i .^{39}$

Officials' incentives. For notational convenience, we write $V(\sigma)$ as shorthand for $V(\sigma, r, s, b)$. Assume an entrepreneur deals directly with her official, that is, $e=\{h, l\}$. The official's interim payoff (i.e., before the realization of $\sigma$ ) is then $V(c)$ if the entrepreneur chooses $e=h$, and $\rho V(n)+(1-\rho) V(c))$ if the entrepreneur chooses $e=l$. Now assume the entrepreneur chooses $e=i$. The official with whom she is paired pockets $p$ from the intermediary, the salary $s_{g}$, and incurs the cost $\gamma$. Hence, the official's payoff is $s_{g}+p-\gamma$. We assume an official maximizes his expected payoff when choosing $p$ (anticipating the probability that the entrepreneur he will be paired with chooses compliance, i.e., $H(\tilde{\psi}))$.

No self-reporting scheme. Officials who grant the permit receive $s_{g}$, and those who deny it receive $s_{d}$. Consider the direct interaction between an official and an entrepreneur. The game the two players play is identical to that in the baseline model. Hence, (3) has to hold to deter bribery, whereas (4) has to hold to deter extortion (see Section 3.2). The two conditions cannot hold jointly, and the optimal

\footnotetext{
${ }^{39}$ To simplify exposition, we assume all entrepreneurs apply for the permit. This assumption is without loss of generality. As in the baseline model, tolerating extortion is never optimal. As a result, the expected payoff of an entrepreneur who does not comply with regulation but applies for the permit (without going through an intermediary) is strictly positive (because $\sigma=c$ with probability $1-\rho$ when $e \neq h$ ).
} 
incentive scheme has to be such that (4) holds. ${ }^{40}$ Therefore, we have $b_{c}=0, b_{n}=G$, and $r=g$ for $\forall \sigma$. In words, permits are always granted, but a bribe equal to $G$ is paid when noncompliance is detected (which occurs with probability $\rho$ ). Let $\tilde{G}$ be a threshold on the private benefit $G$ (see the Appendix).

Proposition 3. If no self-reporting scheme is implemented, the optimal wage schedule is $s_{g}=0$ and $s_{d} \in[0, \gamma]$. Furthermore,

- If $G \leq \tilde{G}$, officials do not deal with intermediaries. The equilibrium is identical to that described in Proposition 1.

- If $G>\tilde{G}$, all noncompliant entrepreneurs obtain the permit via an intermediary at price $p=\frac{\bar{\psi}+\gamma}{2}$. The share of noncompliant entrepreneurs is strictly larger than if intermediaries were unavailable.

In this model, officials collect bribes from intermediaries if and only if the entrepreneurs' willingness to pay for the permit $G$ is large enough. To grasp the intuition, consider that $p$ is bounded from above by $\rho G$, that is, the expected bribe an entrepreneur who does not comply with regulation pays when choosing to bypass the intermediary. As a result, when $G$ is small enough, an official who sells permits to intermediaries cannot do better than to set $p=\rho G$. But, intuitively, when setting this price, the official's expected revenue would be the same as when taking bribes directly. Thus, the official has no reason to deal with the intermediaries. However, when $G$ is large enough, the official can set $p$ below $\rho G$ and obtain a larger expected payoff than when dealing with entrepreneurs directly. The official thereby induces more entrepreneurs to pay bribes to get the permit, although $p$ can be kept large enough to compensate the loss of revenue from inframarginal ones. Note that in a one-shot interaction with an entrepreneur, the official cannot commit to an expected bribe below $\rho G$, even though attracting more "customers" is desirable.

An immediate consequence of Proposition 3 is that intermediaries make noncompliance more pervasive when $G>\tilde{G}$ (and do not affect it otherwise). Indeed, the "price" of an illegitimate permit is lower, and fewer entrepreneurs comply with regulation.

\footnotetext{
${ }^{40}$ We provide an informal argument. Suppose the government did not deter extortion. Any entrepreneur complying with regulation would have to pay a bribe $b=G$ to obtain the permit. Hence, her payoff would be nonpositive, implying that no entrepreneur would comply. Clearly, this outcome cannot be socially optimal.
} 
Corollary. Suppose the government does not implement a self-reporting scheme. Banning intermediaries would be socially desirable if and only if $G>\tilde{G}$.

In reality, cracking down on intermediaries is hard, for instance, because many operate informally. Thus, the government has no choice but to provide officials with strong enough incentives to refuse to sell permits via intermediaries. However, just like in our baseline model, the risk of opening the door to extortion makes this objective elusive.

Implementing a self-reporting scheme. We restrict attention to the case in which $G>\tilde{G}$, because we are interested in situations in which, in its absence, the equilibrium is such that officials sell permits to intermediaries (see Proposition 3 above). Furthermore, we do not characterize the optimal incentive scheme. Rather, we establish the existence of a scheme that (i) makes deterring both extortion and bribery (direct as well indirect) possible, and (ii) increases social welfare. The mechanism we characterize is close in spirit to that of Lemma 1: officials are rewarded only when their entrepreneurs self-report, that is, $s_{a} \geq G-\gamma>s_{d}=s_{g}=0$.

Proposition 4. Assume $G>\tilde{G}$. By setting $s_{a}=\bar{s} \equiv \frac{\bar{\psi}^{2}-\gamma^{2}}{4 \rho(\bar{\psi}-\rho G)}>s_{d}=s_{g}=0$, the government can deter all forms of corruption, including indirect bribery. Also, a threshold $D^{I}$ exists such that, when $D>D^{I}$, social welfare is strictly higher under the self-reporting scheme.

The logic underpinning this scheme is identical to the baseline model. To fully deter bribery, however, the government also needs to make sure officials do not sell permits through intermediaries. This requires raising $s_{a}$ up to $\bar{s}$ (observe that the optimal $s_{d}$ in absence of intermediaries, as stated in Proposition 2, is equal to $G-\gamma$, which is smaller than $\bar{s}$ ). When the expected gain from catching noncompliant entrepreneurs is large enough, officials prefer not to deal with intermediaries. A straightforward implication is that the wage bill associated with the self-reporting scheme is higher than if intermediaries were absent. This is not surprising: intermediaries make sustaining bribery easier, and thus force the government to pay higher bonuses to deter it.

\section{Conclusion}

One of the most detrimental consequences of corruption is that it undermines regulations aiming to protect society from risks and hazards. In this paper, we have made the case for a simple self-reporting 
scheme that enables the government to deter corruption and improve regulatory enforcement. We have also shown that the presence of bureaucratic intermediaries can make the self-reporting scheme even more desirable.

We believe the incentive scheme developed in this paper could be helpful in other settings beyond the one we have considered here. A first example is the collection of taxes and customs duties, where inspectors may be tempted to both collect bribes from violators and to extort money from compliant tax payers (Hindriks et al. (1999), Sequeira and Djankov (2013)). The enforcement of traffic law provides another potential application. Trucking firms are generally required to respect ceilings on truck weight, and officials manning the weigh stations are often corrupt (Olken and Barron (2009), Foltz and Bromley (2014)). Presumably, the scheme we propose could allow the government to deter corruption and increase compliance with weight requirements. When implementing the self-reporting scheme, the government could promise to reduce sanctions on firms or drivers if they acknowledge their own noncompliance.

Finally, we also believe the mechanism we propose can be applied to tackle collusion and abuses of authority within firms. As previous literature has pointed out, it is not uncommon for supervisors to collude with, and harass, subordinates (see, e.g., Tirole (1992), Khalil et al. (2010)). Although the ultimate objective of a principal might be to maximize profit rather than social welfare, the mechanism we propose could also help deter abuses by supervisors. 


\section{Appendix}

\section{Preliminaries}

Suppose the government has delegated authority over permits to the officials, and consider a given entrepreneur-official pair. Because the government does not communicate with the officials, we let $m$ denote a given message sent by the entrepreneur. We introduce the following notation.

- We denote by $r_{\sigma}^{\prime}$ (resp. $m_{\sigma}^{\prime}$ ) the official's equilibrium ruling (resp. the entrepreneur's equilibrium message) played in the subgame that follows the entrepreneur's rejection of the official's deal, for a given $\sigma$.

- We write $U(\psi, e, r, m, b) \equiv u(r, m)-\psi I(e)-b$, where $I(h)=1$ and $I(l)=0$. We denote by $u_{\sigma}^{\prime} \equiv u\left(r_{\sigma}^{\prime}, m_{\sigma}^{\prime}\right)$ the payoff obtained by the entrepreneur in the absence of a deal with the official and $V_{\sigma}^{\prime} \equiv V\left(\sigma, r_{\sigma}^{\prime}, m_{\sigma}^{\prime}\right)$ the corresponding payoff of the official.

- We denote by $b_{\sigma}$ the equilibrium bribe following the entrepreneur's acceptance of the official's deal, for a given $\sigma$. The bribe $b_{\sigma}$ is the solution to problem (1).

Lemma A.1 is useful in limiting the number of cases to consider in the proofs to come.

\section{Lemma A.1}

Any schedule of wages that leads to $u_{c}^{\prime}=u_{n}^{\prime}$ results in a nonpositive level of social welfare. Therefore, any such schedule cannot be optimal.

Proof. The problem of an official when offering a deal to an entrepreneur can be written as follows:

$$
\begin{array}{ll}
\max _{\left\{r, m_{E}, b\right\}} & s_{r, m}-\gamma+b \quad \text { subject to } \\
& u(r, m)-\psi I(e)-b \geq u_{\sigma}^{\prime}-\psi I(e),
\end{array}
$$


and also subject to $m$ being chosen in a sequentially rational way by the entrepreneur. Clearly, if a deal exists, $b_{\sigma}=u(r, m)-u_{\sigma}^{\prime}, \forall \sigma$, and the payoff of an entrepreneur as a result of the deal is $u_{\sigma}^{\prime}$, regardless of $r$ and $m$. Recall also that, when no deal is struck, the payoff of an entrepreneur is $u_{\sigma}^{\prime}$ by definition. It follows that if $u_{c}^{\prime}=u_{n}^{\prime}$, no entrepreneur chooses to comply, because her payoff is independent of $\sigma$ (and thus also independent of $e$ ), so that social welfare is bounded from above by zero.

\section{Proof of Proposition 1}

We first prove that it is (weakly) optimal to delegate authority over the permits to the officials. We then characterize the government's optimal policy.

\section{Proof that Delegating Authority to Officials is Weakly Optimal}

Suppose the government retains authority over permits and communicates with the officials. Recall $M_{O} \in\left\{m_{O_{1}}, m_{O_{2}}\right\}$ denotes the officials' message space and $m_{O}$ denotes a given message. The government chooses the schedule $s\left(m_{O}\right): M_{O} \rightarrow \mathbb{R}^{+}$and the decision-rule $r\left(m_{O}\right): M_{O} \rightarrow\{g, d\}$. We first show setting $r_{m_{O 1}} \neq r_{m_{O 2}}$ is optimal. Suppose $r_{m_{O 1}}=r_{m_{O 2}}=g$. Under this policy, all entrepreneurs apply for the permit, all choose $e=l$, and all obtain the permit without paying bribes (entrepreneurs would reject any requests for bribes). As a result, welfare is negative (because $G<D)$, and the government would be better off, for instance, by forbidding the activity. Now suppose $r_{m_{O 1}}=r_{m_{O 2}}=d$. Under this policy, no entrepreneur applies for the permit and welfare is equal to zero. It follows setting $r_{m_{O 1}} \neq r_{m_{O 2}}$ is weakly optimal. Because, when $r_{m_{O 1}} \neq r_{m_{O 2}}$, officials de facto exercise full discretion over permits, the government may as well delegate authority to them, and let the schedule of wages be a mapping such that $s(r):\{g, d\} \rightarrow \mathbb{R}^{+}$.

\section{Computing the Government's Optimal Policy}

Suppose the government delegates authority over the permits to the officials. We first describe the outcome of the subgame that takes place if the entrepreneur and official do not strike a deal. Next, we describe the conditions under which the two parties strike a deal, and the resulting outcome. Finally, we characterize the optimal schedule of wages. 


\section{No deal}

We first compute $r_{\sigma}^{\prime}$ and $u_{\sigma}^{\prime}$ for $\forall \sigma$. In the absence of a deal, an official obtains $s_{g}-l(\sigma, g) \gamma$ if $r=g$ and $s_{d}-l(\sigma, d) \gamma$ if $r=d$, where $l(\sigma, g)=1$ (resp. $l(\sigma, d)=1$ ) if $\sigma=n$ (resp. $\left.\sigma=c\right)$, and zero otherwise. Therefore, if $s_{d}>s_{g}+\gamma$, then $r_{\sigma}^{\prime}=d$ for $\forall \sigma$, and thus $u_{\sigma}^{\prime}=0$ for $\forall \sigma$. If $s_{g}+\gamma \geq s_{d} \geq s_{g}-\gamma$, then $r_{c}^{\prime}=g$ and $r_{n}^{\prime}=d$. Thus, $u_{c}^{\prime}=G$ and $u_{n}^{\prime}=0$. Finally, if $s_{g}-\gamma>s_{d}$, then $r_{\sigma}^{\prime}=g$ for $\forall \sigma$, and thus $u_{\sigma}^{\prime}=G$ for $\forall \sigma$. Applying Lemma A.1, no loss of generality occurs in restricting our attention to schedules of wages satisfying $s_{g}+\gamma \geq s_{d} \geq s_{g}-\gamma$. Thus, $r_{c}^{\prime}=g$ and $r_{n}^{\prime}=d$, so that $u_{c}^{\prime}=G$ and $u_{n}^{\prime}=0$. Furthermore, $V_{c}^{\prime}=s_{g}$ and $V_{n}^{\prime}=s_{d}$.

\section{Deal}

We now characterize the conditions under which an official strikes a deal with an entrepreneur. Assume the deal entails the permit being granted, that is, $r_{\sigma}=g$. To determine $b_{c}$, the official maximizes $s_{g}-\gamma+b_{c}$ subject to $G-b_{c} \geq u_{c}^{\prime}=G$, which yields $b_{c}=0$. To determine $b_{n}$, the official maximizes $s_{g}-\gamma+b_{n}$ subject to $G-b_{n} \geq u_{n}^{\prime}=0$, which yields $b_{n}=G$. As a result, $V(c, g, 0)=s_{g}$ and $V(n, g, G)=s_{g}-\gamma+G$.

Now assume the deal entails the permit being denied, that is, $r_{\sigma}=d$. To determine $b_{c}$, the official chooses its highest possible value subject to $-b_{c} \geq u_{c}^{\prime}=G$, which yields $b_{c}=-G$. To determine $b_{n}$, the official chooses its highest possible value subject to $-b_{n} \geq u_{n}^{\prime}=0$, which yields $b_{n}=0$. As a result, $V(c, d,-G)=s_{d}-G-\gamma$ and $V(n, d, 0)=s_{d}$. Comparing these payoffs to $V(c, g, 0)$ and $V(n, g, G)$, and using the fact that $G>2 \gamma$, one straightforwardly derives that the official never chooses the deals involving $r=d$.

Finally, comparing $V(c, g, 0)=s_{g}$ and $V(n, g, G)=s_{g}-\gamma+G$ to $V_{c}^{\prime}$ and $V_{n}^{\prime}$, we derive the official does not offer a deal when $\sigma=c$, so that $r_{c}=g$ and $b_{c}=0$. By contrast, when $\sigma=n$, the official offers a deal if and only if $s_{g}-\gamma+G>s_{d}$. This condition holds because $s_{g}+\gamma \geq s_{d}$ and $G>2 \gamma$. As a result, $r_{n}=g$ and $b_{n}=G$. 


\section{Optimal schedule of wages}

An entrepreneur intent on applying chooses $e=h$ if and only if $G-b_{c}-\psi \geq \rho\left(G-b_{n}\right)+$ $(1-\rho)\left(G-b_{c}\right)$, which simplifies to $\rho G \geq \psi$. Because $\rho\left(G-b_{n}\right)+(1-\rho)\left(G-b_{c}\right)=(1-\rho) G>0$, all entrepreneurs apply for the permit. Also, a fraction $H(\rho G)$ of entrepreneurs chooses $e=h$, and the rest choose $e=l$. As argued above, the optimal incentive scheme must satisfy $s_{g}+\gamma \geq s_{d} \geq s_{g}-\gamma$. Therefore, the government chooses $\left\{s_{g}, s_{d}\right\}$ to maximize

$$
W=\int_{0}^{\rho G}(G-\psi) d H(\psi)+\int_{\rho G}^{\bar{\psi}}(G-D-\rho \gamma) d H(\psi)-(\lambda-1) s_{g},
$$

subject to $s_{d} \in\left[s_{g}-\gamma, s_{g}+\gamma\right]$. The solution is such that $s_{g}=0$ and $s_{d} \in[0, \gamma]$. Moreover, expression (11), plugging in $s_{g}=0$, is strictly positive if and only if $D<D_{0}^{N S} \equiv \frac{G-\int_{0}^{\rho G} \psi d H(\psi)}{1-H(\rho G)}-\rho \gamma$. Therefore, when this inequality holds, setting $s_{g}=0$ and $s_{d} \in[0, \gamma]$ is socially optimal. Otherwise, the government bans the activity.

\section{Proof of Proposition 2}

We structure the proof as follows. In Part I, we assume the self-reporting scheme is in place:

1. the government denies the permit to all entrepreneurs who send message $m_{E 1}$,

2. whether the entrepreneurs who send message $m_{E 2}$ obtain the permit is left to the discretion of their official, and

3. the government sets $s_{a} \equiv s_{m_{E 1}}, s_{g} \equiv s_{g, m_{E 2}}$, and $s_{d} \equiv s_{d, m_{E 2}}$.

We compute the optimal self-reporting scheme. As we show below, the government can always replicate the level of welfare achieved under the policy outlined in Proposition 1 (i.e., when not communicating with the entrepreneurs). As a result, in Part I, we also compute the conditions under which communicating with the entrepreneurs through the self-reporting scheme improves on the level of welfare achieved when not communicating with the entrepreneurs.

In Part II, we compute an upper bound on the level of welfare any mechanism within the class of mechanisms we consider can achieve. We show the self-reporting scheme achieves this upper bound 
whenever communicating with the entrepreneurs is valuable.

\section{Part I}

We first describe the outcome of the subgame that takes place if an entrepreneur and an official do not strike a deal. Next, we describe the conditions under which the two parties enter a deal, and the resulting outcome of the deal. Finally, we characterize the optimal schedule of wages. Throughout, we suppose the government makes a transfer $G>t \geq 0$ to the entrepreneurs who self-report, and treat $t$ as a choice variable. We allow for this possibility to show that our results are robust to this modification. In this (slightly) modified setup, the government will be able to make entrepreneurs strictly better off by self-reporting when $\sigma=n$. To obtain the results stated in Proposition 2, simply set $t=0$. In what follows, we let $m$ denote a given message sent by an entrepreneur, and set $m_{1}=m_{E 1}$ and $m_{2}=m_{E 2}$. As a result, $s_{a} \equiv s_{m_{1}}, s_{g} \equiv s_{g, m_{2}}$, and $s_{d} \equiv s_{d, m_{2}}$.

\section{No deal}

Consider a given pair and suppose no deal was struck. We first compute the official and entrepreneur's payoffs when the latter has chosen not to self-report (i.e., $\left.m_{\sigma}=m_{2}\right)$. The official obtains $s_{g}-l(\sigma, g) \gamma$ if $r=g$ and $s_{d}-l(\sigma, d) \gamma$ if $r=d$, where $l(\sigma, g)=1$ (resp. $\left.l(\sigma, d)=1\right)$ if $\sigma=n$ (resp. $\sigma=c$ ), and zero otherwise. It follows that if $s_{g}>s_{d}+\gamma$, then $r_{\sigma}=g$ and $u_{m_{2}, \sigma}=G$ for $\forall \sigma$, where $u_{m_{2}, \sigma}$ denotes the entrepreneur's payoff when choosing not to self-report, for a given $\sigma$. Similarly, if $s_{d}+\gamma \geq s_{g} \geq s_{d}-\gamma$, then $r_{c}=g, u_{m_{2}, c}=G, r_{n}=d$, and $u_{m_{2}, n}=0$. Finally, if $s_{d}-\gamma>s_{g}$, then $r_{\sigma}=d$ and $u_{m_{2}, \sigma}=0$, $\forall \sigma$.

We now analyze the entrepreneur's choice whether to self-report (and forgo the permit). This choice is rational for the entrepreneur if and only if her payoff in the ensuing subgame exceeds $u_{m_{2}, \sigma}$. We consider the three cases highlighted in the previous paragraph in turn. The first is such that $s_{g}>s_{d}+\gamma$. Because $u_{m_{2}, \sigma}=G$ for $\forall \sigma$, the entrepreneur is better off not self-reporting. As a result, $r_{\sigma}^{\prime}=g, m_{\sigma}^{\prime}=m_{2}$, and $u_{\sigma}^{\prime}=G$ for $\forall \sigma$. Now suppose $s_{d}-\gamma>s_{g}$. Because $u_{m_{2}, \sigma}=0 \leq t$, the entrepreneur is better off self-reporting, $\forall \sigma$. As a result, $m_{\sigma}^{\prime}=m_{1}$, and $u_{\sigma}^{\prime}=t, \forall \sigma$. Finally, suppose $s_{d}+\gamma \geq s_{g} \geq s_{d}-\gamma$. Because $u_{m_{2}, c}=G$, the entrepreneur does not self-report when $\sigma=c$. As a 
result, $r_{c}^{\prime}=g, m_{c}^{\prime}=m_{2}, V_{c}^{\prime}=s_{g}$, and $u_{c}^{\prime}=G$. By contrast, because $u_{m_{2}, n}=0 \leq t$, the entrepreneur is better off self-reporting when $\sigma=n$. As a result, $m_{n}^{\prime}=m_{1}, V_{n}^{\prime}=s_{a}$, and $u_{n}^{\prime}=t$.

Therefore, if the official-entrepreneur pair does not strike a deal, the outcome of the ensuing subgame is such that $u_{c}^{\prime}=u_{n}^{\prime}$, except when $s_{d}+\gamma \geq s_{g} \geq s_{d}-\gamma$. By Lemma A.1, we know no loss of generality occurs in restricting attention to $s_{d}+\gamma \geq s_{g} \geq s_{d}-\gamma$.

\section{Deal}

Consider a given pair. Assume the deal specifies $r=d$ and $m=m_{2}$. Because, conditional on $r=d$, the entrepreneur receives $t$ when $m=m_{1}$ and 0 when $m=m_{2}$, deviating is profitable for her. Thus, the deal is not implementable. Assume the deal specifies $m=m_{1}$. Because (i) the official cannot commit to a ruling $r$, which here only occurs out-of-equilibrium (i.e., if the entrepreneur sends $m=m_{2}$ ), (ii) $G>t$, and (iii) the bribe $b$ is sunk, the entrepreneur deviates if choosing $r=g$ is then in the official's interest. Faced with a deviation, the official chooses $r=g$ if and only if $\sigma=c$, because $s_{d}+\gamma \geq s_{g} \geq s_{d}-\gamma$. As a result, a deal specifying $m=m_{1}$ is viable only if $\sigma=n$. However, given that $m_{n}^{\prime}=m_{1}$, note the official's payoff cannot be strictly larger than $V_{n}^{\prime}=s_{a}$ when implementing this deal. The official is thus better off not offering this deal when $\sigma=n$.

It follows that, given $\sigma$, if a deal is struck, it must entail $r_{\sigma}=g$ and $m_{\sigma}=m_{2}$. To determine $b_{c}$, the official maximizes $s_{g}-\gamma+b_{c}$ subject to $G-b_{c} \geq u_{c}^{\prime}=G$, which yields $b_{c}=0$. To determine $b_{n}$, the official maximizes $s_{g}-\gamma+b_{n}$ subject to $G-b_{n} \geq u_{n}^{\prime}=t$, which yields $b_{n}=G-t$. As a result, $V\left(c, g, m_{2}, 0\right)=s_{g}$ and $V\left(n, g, m_{2}, G-t\right)=s_{g}-\gamma+G-t$. Comparing these payoffs to $V_{c}^{\prime}=s_{g}$ and $V_{n}^{\prime}=s_{a}$, we find the official is payoff-indifferent regarding whether to offer a deal when $\sigma=c$. Thus, no deal is struck and $r_{c}=g$ and $b_{c}=0$. Further, when $\sigma=n$, the official offers a deal if and only if $s_{g}-\gamma+G-t>s_{a}$. As a result, $r_{n}=g, m_{n}=m_{2}$, and $b_{n}=G-t$ if $s_{g}-\gamma+G-t>s_{a}$, whereas $m_{n}=m_{1}$ and $b_{n}=0$ otherwise. 


\section{Officials' Optimal Schedule of Wages}

We now determine the optimal schedule $\left\{s_{g}, s_{a}, s_{d}, t\right\}$. We know the optimal schedule of wages is such that $s_{d}+\gamma \geq s_{g} \geq s_{d}-\gamma$. Moreover, we must distinguish between two cases, depending on whether $s_{g}-\gamma+G-t>s_{a}$ holds. For each of these two cases, we characterize the associated expression for social welfare, and the (locally) optimal schedule of wages. We then compare welfare levels to determine the globally optimal scheme.

Assume $s_{g}-\gamma+G-t>s_{a}$. An entrepreneur intent on applying chooses $e=h$ if and only if $G-b_{c}-\psi \geq \rho\left(G-b_{n}\right)+(1-\rho)\left(G-b_{c}\right)$, which simplifies to $\rho(G-t) \geq \psi$. Because $\rho\left(G-b_{n}\right)+(1-\rho)\left(G-b_{c}\right)=\rho t+(1-\rho) G>0$, all entrepreneurs apply for the permit. Also, a fraction $H(\rho(G-t))$ of entrepreneurs chooses $e=h$, and the rest choose $e=l$. Therefore, the government chooses $\left\{s_{g}, s_{a}, s_{d}, t\right\}$ to maximize

$$
\begin{array}{r}
W_{0}^{\rho(G-t)}(G-\psi) d H(\psi)+\int_{\rho(G-t)}^{\bar{\psi}}(G-D-\rho \gamma) d H(\psi)-(\lambda-1) s_{g} \text { s. t. } \\
s_{g} \in\left[s_{d}-\gamma, s_{d}+\gamma\right] \\
s_{g}-\gamma \leq s_{a} \\
s_{g}-\gamma+G-t>s_{a} .
\end{array}
$$

Setting $s_{g}=0, s_{a} \in[0, G-\gamma-t)$, and $s_{d} \in[0, \gamma]$ is optimal because doing so achieves the highest possible value of (12) while satisfying all constraints. Observe also that (12) is decreasing in $t$. In particular, (12) goes to

$$
W=\int_{0}^{\rho G}(G-\psi) d H(\psi)+\int_{\rho G}^{\bar{\psi}}(G-D-\rho \gamma) d H(\psi)
$$

as $t$ goes to 0 . Therefore, a government concerned about whether entrepreneurs who are payoffindifferent whether to self-report indeed prefer to self-report can ensure self-reporting is strictly optimal and achieve a level of welfare arbitrarily close to (13) by setting $t$ arbitrarily close to 0 .

Assume now $s_{g}-\gamma+G-t \leq s_{a}$. An entrepreneur intent on applying chooses $e=h$ if and only if $G-b_{c}-\psi \geq \rho t+(1-\rho)\left(G-b_{c}\right)$, which simplifies to $\rho(G-t) \geq \psi$. Because $\rho\left(G-b_{n}\right)+(1-\rho)\left(G-b_{c}\right)=\rho t+(1-\rho) G>0$, all entrepreneurs apply for the permit. Also, 
a fraction $H(\rho(G-t))$ of entrepreneurs chooses $e=h$, and the rest choose $e=l$. Note, however, that unlike when $s_{g}-\gamma+G-t>s_{a}$, the entrepreneurs for which $\sigma=n$ is realized do not obtain the permit. The government chooses $\left\{s_{g}, s_{a}, s_{d}, t\right\}$ to maximize

$$
\begin{array}{r}
\int_{0}^{\rho(G-t)}(G-\psi) d H(\psi)+\int_{\rho(G-t)}^{\bar{\psi}}(G-D) d H(\psi) \\
-[1-\rho(1-H(\rho(G-t)))](\lambda-1) s_{g}-(1-H(\rho(G-t))) \rho(\lambda-1)\left(s_{a}+t\right) \text { s.t. } \\
s_{g} \in\left[s_{d}-\gamma, s_{d}+\gamma\right], \\
s_{g}-\gamma+G-t \leq s_{a}, \\
s_{g}-\gamma \leq s_{a} .
\end{array}
$$

Notice (14) is decreasing in $s_{g}$ and $s_{a}$. Also, from (15) and (16), $s_{a}$ is bounded from below by $s_{g}+G-\gamma-t$ and $s_{g}-\gamma$. Substituting $s_{a}=s_{g}+G-\gamma-t$ into (14), one immediately derives that setting $s_{g}=0$ is optimal. Moreover, setting $s_{d} \in[0, \gamma]$ ensures the other constraints are indeed satisfied. Also, (14) goes to

$$
\begin{aligned}
W= & \int_{0}^{\rho G}(G-\psi) d H(\psi)+(1-\rho) \int_{\rho G}^{\bar{\psi}}(G-D) d H(\psi) \\
& -(1-H(\rho G)) \rho(\lambda-1)(G-\gamma),
\end{aligned}
$$

as $t$ goes to 0 .Therefore, a government concerned about whether entrepreneurs who are payoffindifferent whether to self-report indeed prefer to self-report can ensure self-reporting is strictly optimal and achieve a level of welfare arbitrarily close to (17) by setting $t$ arbitrarily close to $0 .{ }^{41}$ Observe that (17) is positive if and only if $D \leq D_{0}^{S} \equiv \frac{1}{1-\rho}\left(D_{0}^{N S}-\lambda \rho(G-\gamma)\right)$.

\section{Social Welfare}

The last step involves comparing welfare levels. In what follows, we set $t=0$. Welfare level (17) is

\footnotetext{
${ }^{41}$ This finding establishes the robustness of the self-reforming scheme because it shows that the government can ensure - at an arbitrarily small cost - that entrepreneurs who have not entered a deal are strictly better off self-reporting when $\sigma=n$.
} 
strictly higher than (13) if and only if $D>D^{S} \equiv \lambda(G-\gamma)$. Therefore, this condition must hold for the scheme to be desirable. Further, welfare level (17) is nonnegative if and only if $D \leq D_{0}^{S}$. Thus, this condition must also hold for the scheme to be preferred over banning the activity. Finally, $D_{0}^{S} \geq D^{S}$ if and only if $\lambda \leq \frac{D_{0}^{N S}}{G-\gamma}$. Thus, exploiting entrepreneur reports is optimal whenever $\lambda \leq \frac{D_{0}^{N S}}{G-\gamma}$ and $D^{S}<D \leq D_{0}^{S}$. If $\lambda \leq \frac{D_{0}^{N S}}{G-\gamma}$ and $D \leq D^{S}$, the incentive scheme associated with (13) is optimal: the government does not exploit entrepreneur self-reporting but allows the activity. The same conclusion applies if $\lambda>\frac{D_{0}^{N S}}{G-\gamma}$ and $D \leq D_{0}^{N S}$. Finally, when $\lambda>\frac{D_{0}^{N S}}{G-\gamma}$ and $D>D_{0}^{N S}$, the government bans the activity.

\section{Part II}

We now compute an upper bound on the level of welfare any mechanism within the class of mechanisms we consider can achieve. We show that the level of welfare achieved under the selfreporting scheme (when $t=0$ ) is equal to this upper bound whenever communicating with the entrepreneurs is valuable. The proof proceeds as follows. We first establish that it is without loss of generality for the government to retain authority over permits. We then compute the upper bound. As a corollary result, this proof also establishes that restricting message spaces to contain only two messages is without loss of generality. Indeed, in what follows consider arbitrary message spaces $M_{O}$ and $M_{E}$, where $\left\{m_{O 1}, m_{O 2}\right\} \subseteq M_{O}$ and $\left\{m_{E 1}, m_{E 2}\right\} \subseteq M_{E}$.

\section{Proof that Retaining Authority is Weakly Optimal}

Recall our maintained assumption whereby $m_{E}$ is chosen prior to the ruling $r$ and publicly observable. Consider a given mechanism, with some delegation-rule $x^{*}\left(m_{E}\right): M_{E} \rightarrow\{0,1\}$. Suppose, moreover, that $x^{*}\left(m_{E}\right)=0$ for some (possibly all) message(s) $m_{E}$. Let $\tilde{M}_{E} \equiv\left\{m_{E}: x^{*}\left(m_{E}\right)=0\right\}$, and denote by $s_{g, m_{E}}^{*}$ and $s_{d, m_{E}}^{*}$ the wages specified in the mechanism.

Suppose the government designs an alternative mechanism identical to the previous one in every respect, except that now $x\left(m_{E}\right)=1, \forall m_{E}$, and, moreover, that, $\forall m_{E} \in \tilde{M}_{E}, r_{m_{O 1}, m_{E}}=g$, $r_{m_{O 2}, m_{E}}=d, s_{m_{O 1}, m_{E}}=s_{g, m_{E}}^{*}$, and $s_{m_{O 2}, m_{E}}=s_{d, m_{E}}^{*}$. The equilibrium induced by this alternative equilibrium is identical to that induced under the original mechanism, because officials, when $m_{E} \in \tilde{M}_{E}$, enjoy as much discretionary power over permits as they enjoyed under the original mechanism. It follows there exists no loss of generality in restricting attention to mechanisms such 
that the government retains authority over permits.

\section{Computing an Upper Bounder on the Level of Welfare}

Suppose the government retains authority over permits and communicates with both officials and entrepreneurs. In what follows, let $m \equiv\left(m_{O}, m_{E}\right)$ denote a given pair of messages. We maintain the assumption whereby $m_{E}$ is chosen prior to $m_{O}$. The government chooses the officials' schedule of wages $s\left(m_{E}, m_{O}\right): M_{O} \times M_{E} \rightarrow \mathbb{R}^{+}$and the decision-rule $r\left(m_{E}, m_{O}\right): M_{O} \times M_{E} \rightarrow\{g, d\}$ to maximize expected welfare, where $s_{m}$ and $r_{m}$ denote, respectively, a wage and a decision under a given pair of messages $m$. In case a mechanism induces multiple equilibria, we suppose players coordinate on the government's preferred equilibrium. This assumption is conservative insofar as it can only raise the upper bound on the level of welfare that we are characterize.

Setting $r_{m}=g, \forall m$, cannot be optimal. Systematically granting permits would lead to all entrepreneurs applying for the permit, but none of them choosing $e=h$. As a result, welfare would be negative, and the government would be better off, for instance, by forbidding the activity. Further, setting $r_{m}=d, \forall m$, cannot be strictly optimal. Systematically denying permits would deter all entrepreneurs from applying and welfare would be equal to zero. It follows that, at the optimum, there must exist at least 2 pairs of messages $m$ and $m^{\prime}$, where $m, m^{\prime} \in M_{O} \times M_{E}$, such that $r_{m} \neq r_{m^{\prime}}$.

In what follows, let $m_{\sigma}$, where $\sigma \in\{c, n\}$, denote the equilibrium pair of messages sent by the pairs whose associated signal realization is $\sigma$. It is unimportant for our purposes whether these messages are the outcomes of deals that entrepreneurs and officials enter.

A mechanism $\left\{s\left(m_{E}, m_{O}\right), r\left(m_{E}, m_{O}\right)\right\}$ that would induce $r_{m_{c}}=r_{m_{n}}=d$ (with possibly $m_{c}=m_{n}$ ) cannot be strictly optimal. Indeed, entrepreneurs would anticipate such an outcome when deciding whether to apply, and choose not to apply (leading to a level of welfare equal to zero). ${ }^{42}$ Similarly, a mechanism $\left\{s\left(m_{E}, m_{O}\right), r\left(m_{E}, m_{O}\right)\right\}$ that induces $r_{m_{c}}=d$ and $r_{m_{n}}=g$ cannot be optimal because it either leads to no entrepreneur applying for the permit (and a welfare level equal to zero), or all entrepreneurs applying for the permit and choosing $e=l$ (and a negative level of welfare $).{ }^{43}$ It follows the government must design $\left\{s\left(m_{E}, m_{O}\right), r\left(m_{E}, m_{O}\right)\right\}$ so as to induce either

\footnotetext{
${ }^{42}$ Notice that, in this putative equilibrium, messages are never actually sent to the government because no entrepreneur chooses to apply for the permit. However, for a strategy profile to constitute a subgame perfect equilibrium, one must specify the Nash equilibrium of every subgame.

${ }^{43}$ Which of the two scenarios arises depends on what messages officials and entrepreneurs send when not entering
} 
$r_{m_{c}}=r_{m_{n}}=g$ (with possibly $m_{c}=m_{n}$ ) or $r_{m_{c}}=g$ and $r_{m_{n}}=d$. Notice that, under either outcome, all entrepreneurs whose associated signal realization is $c$ obtain the permit.

We now proceed under the unrealistic assumption that entrepreneurs and officials, when observing $\sigma=c$, are perfectly "obedient": they send whatever messages the government recommends them to send when observing $\sigma=c$, and never enter deals (i.e., do not exchange bribes). However, we maintain the assumption whereby officials and entrepreneurs can enter deals and behave opportunistically when $\sigma=n$. Intuitively, the optimal mechanism under this assumption can only yield a weakly higher level of welfare than the optimal mechanism when corruption and framing are an issue for both $\sigma=n$ and $\sigma=c$. This assumption is therefore conservative insofar as it can only raise the upper bound on the level of welfare that we characterize (and thus make it more difficult for the self-reporting scheme to achieve this upper bound).

Without loss of generality, suppose that the government recommends officials (resp. entrepreneurs) to send message $m_{O 1}$ (resp. $m_{E 1}$ ) when observing $\sigma=c$, and let $m_{1} \equiv\left(m_{O 1}, m_{E 1}\right)$. It follows $r_{m_{c}}=r_{m_{1}}=g$.

Before computing the optimal mechanism, notice that, because $r_{m_{c}}=g$ by assumption, all entrepreneurs apply for the permit. ${ }^{44}$ Further, let $m_{n}^{\prime}$ denote the pair of messages sent in the absence of a deal when $\sigma=n$. The optimal mechanism must necessarily be such that $r_{m_{n}^{\prime}}=d$. To see this, suppose instead $r_{m_{n}^{\prime}}=g$. Under such a scenario, all entrepreneurs would choose $e=l$ (anticipating that they would obtain the permit $\forall \sigma$ ) and welfare would be negative. To summarize, in this modified environment, the optimal mechanism is necessarily such that (i) all entrepreneurs apply for the permit and (ii) $r_{m_{n}^{\prime}}=d$.

Suppose first the government designs $\left\{s\left(m_{E}, m_{O}\right), r\left(m_{E}, m_{O}\right)\right\}$ in a way that induces $r_{m_{n}}=g$ (where therefore $m_{n} \neq m_{n}^{\prime}$ necessarily). In other words, suppose the government lets bribery occur. Setting all transfers equal to zero, recommending officials to send message $m_{O 2}$ when observing $\sigma=n$, and setting $r_{m_{O 2}, m_{E}}=d, \forall m_{E}$, and $r_{m_{O}, m_{E}}=d, \forall m \neq m_{1}$, is optimal: the expected wage bill is equal deals.

${ }^{44}$ For instance, an applicant's expected payoff when choosing $e=l$ is weakly higher than $(1-\rho) G>0$. 
to zero, the highest possible fraction of entrepreneurs chooses $e=l$, and $r_{m_{n}^{\prime}}=d$ indeed holds. ${ }^{45,46}$ The associated level of welfare is equal to

$$
W=\int_{0}^{\rho G}(G-\psi) d H(\psi)+\int_{\rho G}^{\bar{\psi}}(G-D-\rho \gamma) d H(\psi)
$$

that is, the level of welfare achieved by the government when it cannot communicate with entrepreneurs (see (6)). Expression (18) is nonnegative if and only if $D \leq D_{0}^{N S}$.

Suppose now the government designs $\left\{s\left(m_{E}, m_{O}\right), r\left(m_{E}, m_{O}\right)\right\}$ in a way that induces $r_{m_{n}}=d$ (and recall $r_{m_{n}^{\prime}}=d$ ). To achieve this outcome, the government must ensure officials weakly prefer not to enter deals when $\sigma=n$. Because $r_{m_{n}^{\prime}}=d$, the payoff to an official who engages in bribery, ignoring wages, is equal to $G-\gamma \cdot{ }^{47}$ Therefore, officials must necessarily receive a wage weakly higher than $G-\gamma$ not to engage in bribery when $\sigma=n$. Setting all transfers to 0, except for $s_{m_{O 2}, m_{E 1}}=s_{m_{O 2}, m_{E 2}}=G-\gamma$, and setting $r_{m}=d, \forall m \neq m_{1}$, is optimal: it is the cheapest way for the government to deter bribery and it ensures that the highest possible fraction of entrepreneurs choose $e=h .^{48}$ Also, $r_{m_{n}^{\prime}}=d$ indeed holds. The associated level of welfare is equal to:

$$
W=\int_{0}^{\rho G}(G-\psi) d H(\psi)-(1-\rho) \int_{\rho G}^{\bar{\psi}}(D-G) d H(\psi)-\rho(1-H(\rho G))(\lambda-1)(G-\gamma),
$$

that is, the same expression as (9).

Because (i) (18) is the level of welfare the government achieves when not communicating with entrepreneurs and (ii) (19) is the level of welfare achieved under the self-reporting scheme, we conclude that, whenever communicating with the entrepreneurs is valuable, the self-reporting scheme is optimal.

\footnotetext{
${ }^{45}$ Entrepreneurs' incentives to choose $e=h$ are the highest possible because (i) their payoff when $\sigma=c$ is (by assumption) the highest possible (i.e., equal to $G$ ) and (ii) their payoff when $\sigma=n$ is the lowest possible (i.e., equal to 0 ). To see the latter statement, note that bribery occurs when $\sigma=n$, and that officials are able to extract $b=G$ because $r_{m_{n}^{\prime}}=d$.

${ }^{46}$ To see why $r_{m_{n}^{\prime}}=d$, note that, when all wages are equal to 0 and $\sigma=n$, officials are better off sending message $m_{\mathrm{O} 2}$ to avoid the sanction $\gamma$.

${ }^{47}$ One can show entrepreneurs and official can always agree on a feasible deal that involves granting the permit in exchange for a bribe equal to $G$.

${ }^{48}$ Entrepreneurs have the highest possible incentives to choose $e=h$ because their payoff is equal to $G$ when $\sigma=c$ and equal to 0 when $\sigma=n$.
} 


\section{Proof of Proposition 3}

An official chooses $p$ to maximize his expected payoff, computed using $H(\psi)$. Assume noncompliant entrepreneurs use intermediaries. Then, an official's expected payoff is

$$
\begin{aligned}
& H(\tilde{\psi}) \cdot V(c)+(1-H(\tilde{\psi})) \cdot\left(s_{g}+p-\gamma\right) \\
= & H(\tilde{\psi}) \cdot\left(s_{r_{c}}+b_{c}-l\left(c, r, b_{c}\right) \gamma\right)+(1-H(\tilde{\psi})) \cdot\left(s_{g}+p-\gamma\right) .
\end{aligned}
$$

In the expression, $s_{r_{c}}$ and $b_{c}$ denote, respectively, the wage and the (direct) bribe the official collects when $\sigma=c$. The term $l\left(c, r, b_{c}\right)$ equals 1 if $r=d$ and/or if $b_{c}>0$, and 0 otherwise. To interpret this expression, observe that $H(\tilde{\psi})$ is the probability of facing an entrepreneur that chose to comply. By contrast, with probability $1-H(\tilde{\psi})$, the entrepreneur chooses $e=i$, which results in an expected payoff equal to $s_{g}+p-\gamma$. Note that, under our assumptions, $p$ does not affect the size of the pool of potential applicants for an official, but only their compliance effort $e$.

Now assume $U(i)<U(l)$. An official's expected payoff is then equal to

$$
\begin{array}{r}
H(\tilde{\psi}) \cdot V(c)+(1-H(\tilde{\psi})) \cdot(\rho V(n)+(1-\rho) V(c))= \\
H(\tilde{\psi}) \cdot\left(s_{r_{c}}+b_{c}-l\left(c, r, b_{c}\right) \gamma\right) \\
+(1-H(\tilde{\psi})) \cdot\left(\rho\left(s_{r_{n}}+b_{n}-l\left(n, r, b_{n}\right) \gamma\right)+(1-\rho)\left(s_{r_{c}}+b_{c}-l\left(c, r, b_{c}\right) \gamma\right)\right) .
\end{array}
$$

In the expression, $s_{r_{n}}$ and $b_{n}$ denote, respectively, the wage and the bribe when $\sigma=n$, and $l\left(n, r, b_{n}\right)$ is an indicator function equal to 1 if $r=g$ and/or $b_{n}>0$, and 0 otherwise. With probability $H(\tilde{\psi})$ (resp. $1-H(\tilde{\psi})$ ), an official is paired with an entrepreneur who chose $e=h(e=l)$.

In Section 4.1, we argued that tolerating bribery so as to deter extortion is optimal. Recall also that we anticipate, without loss of generality, that all entrepreneurs apply for the permit. Because $b_{c}=0, b_{n}=G$, and $r=g$ for $\forall \sigma$, an entrepreneur chooses $e=h$ if and only if

$$
G-\psi \geq \begin{cases}(1-\rho) G & \text { if } p>\rho G \\ G-p & \text { if } \rho G \geq p\end{cases}
$$


In (20), the right-hand side is the maximum between the expected payoff an entrepreneur enjoys when $e=l$ and that when $e=i$. Because extortion is ruled out, an entrepreneur who complies obtains the permit with probability 1 . Those who do not comply either bribe officials (when detected) or acquire the permit through an intermediary. In the former case, the cost is the expected bribe $\rho G$. In the latter, it is $p$. Hence, when $p>\rho G$, all entrepreneurs who do not comply prefer to deal directly with officials. When $\rho G \geq p$, they all prefer to deal with intermediaries. Hence, $\tilde{\psi}=\min (\rho G, p)$. The fraction of entrepreneurs who comply with regulation is nondecreasing in $p$.

Now consider now the expected payoff of a given official. This payoff can be written as

$$
s_{g}+ \begin{cases}(1-H(\rho G)) \cdot \rho(G-\gamma) & \text { if } p>\rho G \\ (1-H(p)) \cdot(p-\gamma) & \text { if } \rho G \geq p\end{cases}
$$

When $p>\rho G$, the entrepreneur with whom the official is paired does not use an intermediary. Therefore, the official anticipates that the probability of dealing with a noncompliant entrepreneur is $1-H(\rho G)$, and that the expected bribe (net of the lying cost $\gamma$ ) is $\rho(G-\gamma)$. When $\rho G \geq p$, the official knows the entrepreneur with whom he is paired uses an intermediary if noncompliant (i.e., all entrepreneurs for which $\psi \leq p$ choose $e=h$ ). Hence, the probability of dealing with an intermediary is $1-H(p)$, and the payoff is equal to $p-\gamma$. Finally, because bribery is tolerated, the official always grants the permit and pockets $s_{g}$.

We maximize (21) with respect to $p$. For $\forall p>\rho G$, that is, such that the official does not deal with intermediaries, the expected payoff is $V^{N I} \equiv \frac{\bar{\psi}-\rho G}{\bar{\psi}} \cdot \rho(G-\gamma)$. Otherwise, the objective function is $(1-H(p)) \cdot(p-\gamma)=\left(1-\frac{p}{\psi}\right)(p-\gamma)$. The locally optimal $p$ is $\min \left[\rho G, \frac{\bar{\psi}+\gamma}{2}\right]$, which leads to the expected payoff $V^{I} \equiv \max \left[\frac{\bar{\psi}-\rho G}{\bar{\psi}} \cdot(\rho G-\gamma), \frac{(\bar{\psi}-\gamma)^{2}}{4 \bar{\psi}}\right]$. When $G \leq \frac{\bar{\psi}+\gamma}{2 \rho}, V^{I}<V^{N I}$ holds. Hence, the official does not deal with intermediaries (i.e., sets $p>\rho G$ ). When $G>\frac{\bar{\psi}+\gamma}{2 \rho}$, we find $V^{I}>V^{N I}$ if and only if $G>\tilde{G}$, where $\tilde{G}$ is a threshold on $G$ such that $\tilde{G}>\frac{\bar{\psi}+\gamma}{2 \rho}$. To see this, note that $V^{I}>V^{N I}$ can be rewritten as $(2 \rho G-\bar{\psi}-\gamma)^{2}>4 \gamma(1-\rho)(\bar{\psi}-\rho G)$. The left- (resp. right-) hand side of the inequality is strictly increasing (decreasing) with $G$ (conditional on $G>\frac{\bar{\psi}+\gamma}{2 \rho}$ ). Hence, $\tilde{G}>\frac{\bar{\psi}+\gamma}{2 \rho}$ exists such that $V^{I}>V^{N I}$ if and only if $G>\tilde{G}$. To explicitly write $\tilde{G}$, one has to solve the equality $V^{I}=V^{N I}$ for $G$. We forgo this excercise because it is unessential for our argument.

Summing up, the globally optimal $p$ is such that $p>\rho G$ for $G \leq \tilde{G}$, and equal to $\frac{\bar{\psi}+\gamma}{2}$ otherwise. 
Using (20), it follows that when $G \leq \tilde{G}$, a fraction $H(\rho G)$ of entrepreneurs chooses $e=h$, whereas

the remainder choose $e=l$. By contrast, when $G>\tilde{G}$, a fraction $H\left(\frac{\bar{\psi}+\gamma}{2}\right)$ of entrepreneurs chooses $e=h$, whereas the remainder choose $e=i$.

\section{Proof of the Corollary to Proposition 3}

Following Proposition 3, when $G>\tilde{G}$, welfare is equal to

$$
W=\int_{0}^{\frac{\bar{\psi}+\gamma}{2}}(G-\psi) d H(\psi)-\int_{\frac{\bar{\psi}+\gamma}{2}}^{\bar{\psi}}(D-G+\gamma) d H(\psi)-(\lambda-1) s_{g}
$$

Because (4) must hold, setting $s_{g}=0$ and $s_{d} \in[0, \gamma]$ is optimal. Hence,

$$
W=\int_{0}^{\frac{\bar{\psi}+\gamma}{2}}(G-\psi) d H(\psi)-\int_{\frac{\bar{\psi}+\gamma}{2}}^{\bar{\psi}}(D-G+\gamma) d H(\psi)
$$

Now assume $G \leq \tilde{G}$. From Proposition 3, we have that officials do not sell permits to intermediaries. Hence, social welfare is identical to our baseline model, where intermediaries are unavailable (Proposition 1). Following the same steps as in the proof of Proposition 1, one obtains

$$
W=\int_{0}^{\rho G}(G-\psi) d H(\psi)-\int_{\rho G}^{\bar{\psi}}(D-G+\rho \gamma) d H(\psi)
$$

We conclude that if $G>\tilde{G}$, (22) is strictly smaller than (23): welfare would be larger if intermediaries were banned. When $G \leq \tilde{G}$, welfare is the same as if intermediaries were banned.

\section{Proof of Proposition 4}

As stated in the text, we assume $s_{a} \geq G-\gamma>s_{d}=s_{g}=0$. We proceed as follows. We first characterize the equilibrium outcomes when an official and an entrepreneur interact directly. Next, we characterize the outcome when an entrepreneur decides to use an intermediary. Finally, we perform a welfare analysis.

\section{Direct interaction between official and entrepreneur $(e=h, l)$}

Consider a given pair, and assume no deal has been struck. Because of the conditions the incentive scheme satisfies by assumption, one can follow the same steps as in the Proof of Proposition 2 to prove 
the outcome of this subgame is $r_{c}^{\prime}=g, m_{c}^{\prime}=m_{2}$, and $u_{c}^{\prime}=G$. Furthermore, $m_{n}^{\prime}=m_{1}$ and $u_{n}^{\prime}=0$. In words, in the absence of a deal with the entrepreneur, the official grants the permit when $\sigma=c$. By contrast, when $\sigma=n$, the entrepreneur chooses to self-report and is denied the permit. ${ }^{49}$

We now analyze the conditions under which the official strikes a deal with the entrepreneur. Deals entailing $r=d$ can be ruled out following the same steps as in the Proof of Proposition 2 . Furthermore, when $\sigma=c$ and the official proposes a deal entailing $r_{c}=g$ and $m=m_{2}$, no positive bribe exists that the entrepreneur would be willing to pay, because $u_{c}^{\prime}=G$. Therefore, the official is better off not offering a deal and the entrepreneur (official) obtains $G\left(s_{g}=0\right.$ ). Suppose now $\sigma=n$. Because $u_{n}^{\prime}=0$, the official may propose a bribe not larger than $b_{n}=G$ in exchange for $r_{n}=g$. Therefore, because $s_{a} \geq G-\gamma$ by assumption, the official is strictly better off not proposing any deal. As a result, we have $m_{n}=m_{1}$. Hence, when $\sigma=n$, the entrepreneur (official) obtains $0\left(s_{a}\right)$.

Interaction with intermediary $(e=i)$

When interacting with an intermediary, an official grants the permit in exchange for $p$. The entrepreneur (official) obtains $G-p$ (resp., $p-\gamma$ ).

\section{Price setting by the official}

An entrepreneur with cost of compliance $\psi$ chooses $e=h$ if and only if

$$
G-b_{c}-\psi \geq \max \left[(1-\rho)\left(G-b_{c}\right), G-p, 0\right]
$$

which simplifies to $G-\psi \geq \max [(1-\rho) G, G-p]$. Making use of this constraint, and recalling that $s_{g}=0$, an official's expected payoff is equal to

$$
\begin{cases}(1-H(p)) \cdot(p-\gamma) & \text { if } \rho G \geq p \\ (1-H(\rho G)) \cdot \rho s_{a} & \text { if } p>\rho G\end{cases}
$$

Maximizing the above with respect to $p$ yields the following. If $p \leq \rho G$, the official's payoff is $(1-H(p)) \cdot(p-\gamma)=\left(1-\frac{p}{\psi}\right)(p-\gamma)$. The locally optimal $p$ is $\min \left[\rho G, \frac{\bar{\psi}+\gamma}{2}\right]$, which entails an

\footnotetext{
${ }^{49}$ Exactly as in the baseline model, the government can ensure entrepreneurs are strictly better off self-reporting at an arbitrarily small cost.
} 
expected payoff of $\max \left[\frac{\bar{\psi}-\rho G}{\bar{\psi}} \cdot(\rho G-\gamma), \frac{(\bar{\psi}-\gamma)^{2}}{4 \bar{\psi}}\right]$. The payoff is $\left(\frac{\bar{\psi}-\rho G}{\bar{\psi}}\right) \cdot \rho s_{a}$ for $\forall p>\rho G$. As mentioned in the statement of Proposition 4, we restrict attention to $G>\tilde{G}>\frac{\bar{\psi}+\gamma}{2 \rho}$. Hence, the official sets $p=\frac{\bar{\psi}+\gamma}{2}$ if $s_{a}<\bar{s} \equiv \frac{(\bar{\psi}-\gamma)^{2}}{4 \rho(\bar{\psi}-\rho G)}$, and $\rho G<p$ otherwise.

\section{Behavior of entrepreneurs and social welfare}

If $s_{a}<\bar{s}$, so that $p=\frac{\bar{\psi}+\gamma}{2}$, a fraction $H\left(\frac{\bar{\psi}+\gamma}{2}\right)$ of entrepreneurs choose $e=h$, whereas the remainder choose $e=i$. If $s_{a} \geq \bar{s}$, so that $\rho G<p$, a fraction $H(\rho G)$ of entrepreneurs choose $e=h$, whereas the remainder choose $e=l$ and obtain the permit only if $\sigma=c$, that is, with probability $1-\rho$. Thus, conditional on $s_{a}<\bar{s}$, social welfare is equal to

$$
W=\int_{0}^{\frac{\bar{\psi}+\gamma}{2}}(G-\psi) d H(\psi)-\int_{\frac{\bar{\psi}+\gamma}{2}}^{\bar{\psi}}(D-G+\gamma) d H(\psi) .
$$

Now assume $s_{a} \geq \bar{s}$. Social welfare is equal to

$$
W=\int_{0}^{\rho G}(G-\psi) d H(\psi)-(1-\rho) \int_{\rho G}^{\bar{\psi}}(D-G) d H(\psi)-(\lambda-1) \rho(1-H(\rho G)) s_{a}
$$

Setting $s_{a}=\bar{s}$ is clearly optimal. Hence,

$$
W=\int_{0}^{\rho G}(G-\psi) d H(\psi)-(1-\rho) \int_{\rho G}^{\bar{\psi}}(D-G) d H(\psi)-(\lambda-1) \rho(1-H(\rho G)) \bar{s} .
$$

Comparing (24) and (25), we conclude a threshold $D^{I}$ exists such that (24) is smaller than (25) if and only if $D>D^{I}$. 


\section{References}

[1] Abbink, Klaus, Utteeyo Dasgupta, Lata Gangadharan, and Tarun Jain (2014) Letting the briber go free: An Experiment on Mitigating Harassment Bribes. Journal of Public Economics, Vol 111, pp. 17-28.

[2] Aidt, Toke S. (2009), Corruption, Institutions and Economic Development. Oxford Review of Economic Policy, 25 (2): 271-291.

[3] Amegashie, J. A. (2016). The Welfare Effects of Consumers' Reports of Bribery, Journal of Economics and Management Strategy, Vol. 25, Summer 2016, 516-534.

[4] Angelucci, Charles and Martijn Han (2016), Self-Reporting Schemes and Corporate Crime. Columbia Business School Working Paper.

[5] Banerjee, Abhijit (1997), A theory of Misgovernance. Quarterly Journal of Economics, 112 (4): 1289-1332.

[6] Banerjee, Abhijit, Rema Hanna and Sendhil Mullainathan (2012), Corruption. MIT Working Paper 12-08.

[7] Basu, Kaushik (2011), Why, for a Class of Bribes, the Act of Giving a Bribe Should Be Treated as Legal. Working Paper 172011 DEA, Ministry of Finance, Government of India.

[8] Bertrand, Marianne, Simeon Djankov, Rema Hanna and Sendhil Mullainathan (2007), Obtaining a Driver's License in India: An Experimental Approach to Studying Corruption. Quarterly Journal of Economics, vol. 122(4): 1639-1676.

[9] Bose, Gautam and Shubhashis Gangopadhyay (2009), Intermediation in Corruption Markets. Indian Growth Development Review, 2 (2009): 39-55.

[10] Buccirossi, Paolo and Giancarlo Spagnolo (2001), The Effects of Leniency on Illegal Transactions: How (Not) to Fight Corruption, SSE/EFI Working Paper Series in Economics and Finance 456, Stockholm School of Economics.

[11] Buccirossi, Paolo and Giancarlo Spagnolo (2006), Leniency Policies and Illegal Transactions. Journal of Public Economics, Elsevier, vol. 90 (6-7), 1281-1297. 
[12] Burlando, Alfredo and Alberto Motta (2016), Legalize, Tax and Deter: Enforcement Policies for Corruptible Officials. Journal of Development Economics. Volume 118, Pages 207-215.

[13] Callen, Michael and Ali Hasanain (2011), The Punjab Model of Proactive Governance. Mimeo, UCSD.

[14] Celik, Gorkem (2009), Mechanism Design with Collusive Supervision. Journal of Economic Theory, vol. 144(1): 69-95.

[15] Drugov, Mikhail, John Hamman, and Danila Serra (2014), Intermediaries in Corruption: an Experiment. Experimental Economics, 17: 78-99.

[16] Duflo Esther, Michael Greenstone, Rohini Pande, and Nicholas Ryan (2013), Truth Telling by Third Party Auditors and the Response of Polluting Firms: Experimental Evidence from India. Quarterly Journal of Economics;128 (4) :1449-1498.

[17] Dufwenberg, Martin and Giancarlo Spagnolo (2015), Legalizing Bribe Giving. Economic Inquiry, Volume 53, Issue 2, 836-853.

[18] Dusha, Elton. (2015), Intermediated Corruption. International Economic Review, Vol. 56, No. $3,997-1014$.

[19] Faure-Grimaud, Antoine, Jean-Jacques Laffont, and David Martimort, 2003. "Collusion, Delegation and Supervision with Soft Information," Review of Economic Studies, Oxford University Press, vol. 70(2), pages 253-279.

[20] Felli, Leonardo and Rafael Hortala-Vallve (2014), Collusion, Blackmail and Whistleblowing Policy. Working Paper, LSE.

[21] Finan, Frederico, Benjamin A. Olken, and Rohini Pande (2015), The Personnel Economics of the State. NBER Working Paper No. 21825.

[22] Foltz, Jeremy D. and Daniel W. Bromley (2013), Highway Robbery: The Economics of Petty Corruption in West African Trucking. WP, University of Wisconsin.

[23] Fredriksson, Anders (2014), Bureaucracy Intermediaries, Corruption and Red Tape. Journal of Development Economics, Volume 108: 256-273 
[24] Furnivall, John S. (1956), Colonial Policy and Practice: a Comparative Study of Burma and Netherlands India. New York: NYU Press.

[25] Harrington, Joseph (2008), Optimal Corporate Leniency Programs. Journal of Industrial Economics, LVI, 215 - 246.

[26] Hasker, Kevin and Cagla Okten Hasker (2008), Intermediaries and Corruption. Journal of Economic Behavior and Organization, 67: 103-115

[27] Hindriks, Jean, Michael Keen, and Abhinay Muthoo (1999), Corruption, Extortion and Evasion. Journal of Public Economics 74: 395-430.

[28] Innes, Robert (1999). Remediation and Self-Reporting in Optimal Law Enforcement. Journal of Public Economics 72: 379-393.

[29] Kahn, Charles M., Emilson, C. D. Silva, and James P. Ziliak (2001), Performance-Based Wages in Tax Collection: The Brazilian Tax Collection Reform and its Effects. Economic Journal 111: $188-205$.

[30] Kahn, Adnan Q., Asim I. Khwaja, and Benjamin A. Olken (2014), Tax Farming Redux: Experimental Evidence on Performance Pay for Tax Collectors. NBER Working Paper No. 20627.

[31] Kaplow, Louis and Steven Shavell (1994). Optimal Law Enforcement with Self-Reporting of Behavior. Journal of Political Economy 102: 583-606.

[32] Khalil, Fahad, Jacques Lawarrée and Sungho Yun (2010), Bribery versus Extortion: Allowing the Lesser of Two Evils. RAND Journal of Economics, vol. 41(1): 179-198.

[33] Laffont, Jean-Jacques and Jean Tirole (1993). A Theory of Incentives in Procurement and Regulation. Cambridge, Mass.: MIT Press.

[34] Mishra, Ajit (2006), Corruption, Hierarchies and Bureaucratic Structure. In Rose-Ackerman S. and Tina Søreide (eds.) International Handbook of the Economics of Corruption, vol. 1. Edgar Elgar.

[35] Mishra, Ajit and Dilip Mookherjee (2013), Controlling Collusion and Extortion: The Twin Faces of Corruption. Working Paper, Boston University. 
[36] Mookherjee, Dilip and I. P. L. Png (1992), Monitoring vis-a-vis Investigation in Enforcement of Law. American Economic Review 82: 556-565.

[37] Motta, Massimo, and Michele Polo (2003). Leniency Programs and Cartel Prosecution. International Journal of Industrial Organization, 21(3), 347-379.

[38] Oak, Mandar (2015), Legalization of Bribe Giving when Bribe Type Is Endogenous. Journal of Public Economic Theory, 17: 580-604. doi: 10.1111/jpet.12149

[39] OECD (2013), Anticorruption Reforms in Eastern Europe and Central Asia. OECD Publishing.

[40] Olken, Benjamin A. (2007), Monitoring Corruption: Evidence from a Field Experiment in Indonesia. Journal of Public Economics 115 (2): 200-249.

[41] Olken, Benjamin A. and Patrick Barron (2009), The Simple Economics of Extortion: Evidence from Trucking in Aceh. Journal of Political Economy 117 (3): 417-252.

[42] Olken, Benjamin A. and Rohini Pande (2012), Corruption in Developing Countries. Annual Review of Economics, Annual Reviews, vol. 4(1): 479-509, 07.

[43] Perrotta Berlin, Maria and Giancarlo Spagnolo (2015), Leniency, Asymmetric Punishment and Corruption: Evidence from China. Stockholm School of Economics, Working Paper.

[44] Polinsky, A. Mitchell, and Steven Shavell (2000), Corruption and Optimal Law Enforcement. Journal of Public Economics 81: 1-24.

[45] Prendergast, Canice (2003), The limits of Bureaucratic Efficiency. Journal of Political Economy 111: 929-959.

[46] Sequeira, Sandra, and Simeon Djankov (2013), Corruption and Firm Behavior. Working Paper, LSE.

[47] Shleifer, Andrei, and Robert W. Vishny. "Corruption." The Quarterly Journal of Economics 108, no. 3 (1993): 599-617.

[48] Spagnolo, Giancarlo (2005). Divide et Impera: Optimal Leniency Programs. Mimeo Stockholm School of Economics. 
[49] Tirole, Jean (1992), Collusion and the Theory of Organizations. In J. J. Laffont (ed.), Advances in Economic Theory, Vol. 2: 151-206.

[50] Vafaï, Kouroche (2012), Opportunism in Organizations. Journal of Law, Economics, 6 Organization, 26: 158-181.

[51] Wu, Kevin and Klaus Abbink (2013), Reward Self-Reporting to Deter Corruption: An Experiment on Mitigating Collusive Bribery. No 42-13, Monash Economics Working Papers. 